\title{
Robust and Functional Immunity up to 9 months after SARS-CoV-2 infection: a
}

$\underline{\text { Southeast Asian longitudinal cohort. }}$

4 Vo Hoa Thi My ${ }^{1, *}$, Maestri Alvino ${ }^{1, *}$, Auerswald Heidi ${ }^{2}$, Sorn Sopheak ${ }^{3}$, Lay Sokchea ${ }^{1}$, Heng

$5 \quad$ Seng $^{4}$, Sann Sotheary ${ }^{1}$, Ya Nisa $^{1}$, Pean Polidy $^{1}$, Dussart Philippe ${ }^{2}$, Schwartz Olivier $^{5}$, Ly

6 Sovann $^{4}$, Bruel Timothee ${ }^{5}$, Ly Sowath ${ }^{3}$, Duong Veasna ${ }^{2}$, Karlsson Erik A ${ }^{2, \$}$, Cantaert

$7 \quad$ Tineke ${ }^{1, \$}$

$9{ }^{1}$ Immunology Unit, Institut Pasteur du Cambodge, Institut Pasteur International Network,

10 Phnom Penh, Cambodia

$11{ }^{2}$ Virology Unit, Institut Pasteur du Cambodge, Institut Pasteur International Network, Phnom

12 Penh, Cambodia

$13{ }^{3}$ Epidemiology and Public Health Unit, Institut Pasteur du Cambodge, Institut Pasteur

14 International Network, Phnom Penh, Cambodia

$15{ }^{4}$ Cambodian CDC-MoH

$16{ }^{5}$ Virus \& Immunity Unit, Department of Virology, Institut Pasteur, CNRS UMR3569, Paris,

17 France

18

22 *co-first authors, ${ }^{\$}$ co-last authors, correspondence to ekarlsson@ pasteur-kh.org or

23 tineke.cantaert@pasteur.fr 


\section{$24 \underline{\text { Abstract }}$}

25 Assessing the duration of humoral and cellular immunity remains key to overcome the current

26 SARS-CoV-2 pandemic, especially in understudied populations in least developed countries.

27 Sixty-four Cambodian individuals with laboratory-confirmed infection with asymptomatic or

$28 \mathrm{mild} /$ moderate clinical presentation were evaluated for humoral immune response to the viral

29 spike protein and antibody effector functions during acute phase of infection and at 6-9 months

30 follow-up. Antigen-specific B cells, $\mathrm{CD} 4^{+}$and $\mathrm{CD}^{+} \mathrm{T}$ cells were characterized, and $\mathrm{T}$ cells

31 were interrogated for functionality at late convalescence. Anti-spike (S) antibody titers

32 decreased over time, but effector functions mediated by S-specific antibodies remained stable.

33 S- and nucleocapsid (N)-specific B cells could be detected in late convalescence in the activated

34 memory B cell compartment and are mostly $\mathrm{IgG}^{+} . \mathrm{CD}^{+}$and $\mathrm{CD}^{+} \mathrm{T}$ cell immunity was

35 maintained to $\mathrm{S}$ and membrane (M) protein. Asymptomatic infection resulted in decreased

$36 \mathrm{ADCC}$ and frequency of SARS-CoV-2-specific CD4 ${ }^{+} \mathrm{T}$ cells at late convalescence. Whereas

37 anti-S antibodies correlated with S-specific B cells, there was no correlation between $\mathrm{T}$ cell

38 response and humoral immunity. Hence, all aspects of a protective immune response are

39 maintained up to nine months after SARS-CoV-2 infection in the absence of re-infection.

\section{One sentence summary}

44 Functional immune memory to SARS-CoV-2, consisting of polyfunctional antibodies, memory

45 B cells and memory T cells are maintained up to nine months in a South-East Asian cohort in

46 the absence of re-infection. 


\section{$47 \quad$ Introduction}

In December 2019, a cluster of severe pneumonia of unknown cause was reported to the

49 World Health Organization. Investigation into the etiology revealed a novel betacoronavirus,

50 subsequently named Severe Acute Respiratory Syndrome Coronavirus 2 (SARS-CoV-2), the

51 causative agent of Coronavirus Disease 2019 (COVID-19) (1). Clinical spectrum of COVID-

5219 ranges from asymptomatic, over mild upper respiratory tract illness, to severe viral

53 pneumonia resulting in respiratory failure and death (1-3).

Upon infection with SARS-CoV-2, humans generate SARS-CoV-2-specific antibodies,

55 memory $\mathrm{B}$ cells, and $\mathrm{CD} 4^{+}$and $\mathrm{CD} 8^{+} \mathrm{T}$ cells, which all have complementary functions in the

56 clearance of SARS-CoV-2 virions and infected cells (4). Mainly structural proteins are targeted

57 by the immune response, such as the membrane (M) and spike (S) protein integrated in the

58 virion envelope, and the nucleoprotein $(\mathrm{N})$, which protects the RNA genome (5-7). The S

59 protein consists of two domains. The S1 region contains the receptor binding domain (RBD)

60 which interacts with the host protein Angiotensin-converting enzyme 2 (ACE2) to mediate cell

61 entry, whereas the S2 domain mediates membrane fusion. The S1 domain with the RBD is a

62 major target of neutralizing antibodies $(8,9)$. Several studies show correlation between

63 antibodies targeting $S$ and functional neutralization (10-12). In animal models, these

64 neutralizing antibodies are protective against secondary infection $(13,14)$. In humans, anti-S

65 antibodies and neutralizing antibodies can be detected up to one year post infection (15-17).

Besides neutralization, antibodies activate a variety of effector functions mediated by

67 their Fc domain. These include complement activation, killing of infected cells and

68 phagocytosis of viral particles (18). Indeed, it has been shown that symptomatic and

69 asymptomatic SARS-CoV-2 infection elicit polyfunctional antibodies targeting infected cells 
$70(19,20)$ and Fc mediated effector activity of antibodies correlates with reduced disease severity

71 and mortality after SARS-CoV-2 infection (21). However, the evolution of this response over

72 time requires further investigation $(22,23)$.

73 Persistence of serum antibodies may not be the sole determinant of long-lasting

74 immunity post infection or vaccination. Anamnestic recall of memory $\mathrm{T}$ and $\mathrm{B}$ cell populations

75 can also reduce infection or disease at re-exposure (24-26), with increasing importance as

76 antibody titers wane. Virus-specific memory T and B cells can be detected in at least $50 \%$ of

77 the individuals six months post infection $(24,26,27)$. Several studies suggest that increased

78 severity of COVID-19 induces a stronger SARS-CoV-2-specific CD4 ${ }^{+} \mathrm{T}$ cell response (27-29).

79 However, the magnitude, quality, and protective capacity of cellular responses against SARS-

80 CoV-2 requires further definition (4).

81 Kinetics and duration of the memory immune responses could depend on a number of

82 factors including viremia, disease severity, re-infection, cross-reactivity with human seasonal

83 coronaviruses (hCoVs), ethnic background, and age (reviewed in (4)). Other human

84 betacoronaviruses, such as hCoV OC43 and HKU1, and zoonotic viruses, such as SARS-CoV-1

85 and Middle East respiratory syndrome-related coronavirus (MERS-CoV), show waning

86 antibody levels as soon as three months post infection. In contrast, $\mathrm{T}$ cell responses are

87 detectable up to 17 years later $(30,31)$.

Most studies analyzing the evolution of the adaptive immune response to SARS-CoV-

892 are conducted in Caucasian populations (4). In South-East Asia, very few studies have been

90 performed, which mainly focused on antibody responses (16, 32-34). Understanding long-term

91 immunity after natural infection by determining the frequency, function, and specificities of the 
92 humoral and cellular immune components in various populations is critical. Paucity of data

93 from at risk areas and populations can hamper global mitigation and vaccination efforts.

94 We comprehensively characterized long-lived immunity in 64 Cambodian individuals

95 with laboratory-confirmed infection experiencing mild/moderate or asymptomatic clinical

96 outcome. Cambodia remained almost completely COVID-19-free in 2020 (35), hence,

97 additional exposure to SARS-CoV-2 in this cohort is highly unlikely. The humoral immune

98 response to the viral spike protein was assessed and antibody effector functions were

99 characterized during the acute phase of infection and up to nine months later. In addition, at late

100 convalescence, persistence and phenotype of S1- and N-specific memory B cells was evaluated.

101 Virus-specific $\mathrm{CD}^{+}$and $\mathrm{CD}^{+} \mathrm{T}$ cells were characterized and $\mathrm{T}$ cells were interrogated for

102 functionality.

$104 \underline{\text { Results }}$

105 Long-term follow-up of SARS-CoV-2 imported cases

106 Sixty-four individuals with confirmed SARS-CoV-2 were included and re-assessed 6-9 months

107 after infection. SARS-CoV-2 infection was confirmed by positive molecular diagnosis as part

108 of the national surveillance system. Since Cambodia had minimal detection of SARS-CoV-2

109 during the follow-up period, the probability of re-exposure to SARS-CoV-2 was minimal (35)

110 in 2020 . For 33 individuals, we obtained a blood sample 2-9 days after laboratory confirmed

111 infection (Figure S1A). For all 64 study participants, between 1 to 15 follow-up

112 nasopharyngeal/oropharyngeal (NP/OP) swab samplings assessed the duration of viremia

113 during the acute phase of infection via RT-PCR (36). Based on the duration of viremia, 53\% of

114 individuals were considered "long shedders" with detection of viral RNA in NP/OP swabs for 
$115 \geq 10$ days (Figure S1B). Overall, $70 \%$ of the patients displayed mild or moderate symptoms,

116 and 30\% remained asymptomatic (Table S1). For all assays, samples were selected based on

117 availability and quality.

118 Asymptomatic and mild/moderate infection induces a persisting anti-spike antibody response.

119 The presence of S-binding antibodies was measured using the S-Flow assay, which sensitively

120 and quantitatively measures anti-S IgG, $\operatorname{IgA}$, and $\operatorname{IgM}$ by flow cytometry $(19,37)$ (Figure $1 \mathrm{~A})$.

121 The National Institute for Biological Standards and Control (NIBSC) references were utilized

122 to validate the assays and pre-pandemic samples obtained from nineteen individuals were

123 measured to set the cutoff for each assay (Figure S2). Anti-S IgM, IgG, and IgA titers decreased

124 significantly between acute phase and late convalescence $(\mathrm{p}=0.02, \mathrm{p}<0.0001, \mathrm{p}<0.0001$,

125 respectively). (Figure 1B). Within the total S-binding antibodies, the percentage of anti-S IgM

126 and $\operatorname{IgA}$ decreased whereas anti-S $\operatorname{IgG}$ increased over time ( $p=0.0003$, Figure $1 \mathrm{C})$. The

127 detection of neutralizing antibodies was achieved by foci reduction neutralization test using a

128 Cambodian SARS-CoV-2 isolate. There was no difference in the titers of SARS-CoV-2

129 neutralizing antibodies between the acute and convalescent phase, even though titers tended to

130 decrease over time (Figure 1D). Over time, the percentage of individuals positive for anti-S

$131 \operatorname{IgM}(\mathrm{p}<0.0001)$ and anti-S $\operatorname{IgA}(\mathrm{p}<0.0001)$ decreased (Figure 1E). In the acute phase, $91 \%$ of

132 individuals were positive for anti-S IgG, and only $70 \%$ of the individuals were positive for

133 neutralizing antibody titers. Up to nine months post infection, the frequency of individuals

134 positive for anti-S IgG remained stable (88\%) whereas the frequency of individuals with

135 neutralizing titers decreased to $56 \%(\mathrm{p}=0.055)$ (Figure 1E). Analyzing only individuals with

136 paired samples available, revealed similar results as the whole cohort (Figure S3, A-B). Taken 
137 together, these data show that despite decreases in antibody titers over time, the percentage of

138 individuals positive for anti-S IgG remains stable.

139 Functional antibody response changes over time post SARS-CoV-2 infection

140 Besides neutralization, antibodies can mediate Fc-effector functions, such as complement

141 activation, killing of virus-infected cells and phagocytosis of viral particles (18). To further

142 define the humoral response in these individuals, we assessed antibody effector functions in

143 vitro. The NIBSC references were utilized to validate the assays and nineteen pre-pandemic

144 samples were measured to set the cutoff for each assay. Antibody-dependent cellular

145 phagocytosis (ADCP) assay measures the engulfment of neutravidin beads coated with SARS-

146 CoV-2 derived S1 by THP-1 cells (Figure 2A, S4). A decrease in ADCP can be observed

147 between the acute and late convalescent phase $(\mathrm{p}=0.005$, Figure $2 \mathrm{~B}, \mathrm{C})$. The percentage of

148 subjects with ADCP activity decreased from $73 \%$ to $55 \%$ over time. However, when calculating

149 the proportion of ADCP within the total anti-S antibodies, we observed a significant increase

150 of the proportion of ADCP over time ( $\mathrm{p}=0.003$, Figure $2 \mathrm{D})$.

151 Next, to evaluate the contribution of anti-S antibodies to complement dependent

152 cytotoxicity (CDC), we assessed cell death in Raji cells engineered to express $\mathrm{S}$ protein in the

153 presence of normal human serum as source of complement (Figure 2E, S5) (19). No differences

154 in CDC activity was observed between the acute and late convalescent phase, where $60 \%$ and

$15556 \%$ of the subjects showed CDC activity, respectively (Figure 2F, G). The proportion of CDC-

156 mediating antibodies within the total anti-S antibody fraction significantly increased between

157 acute and late convalescence $(\mathrm{p}=0.0002$, Figure $2 \mathrm{H})$.

158 Killing of virus-infected cells can also be mediated by activated NK cells, after binding

159 of immunocomplexes to CD16 (18). Therefore, antibody-dependent cellular cytotoxicity 
(ADCC) activity was measured using S-expressing 293T cells as target cells with degranulation measured by CD107a staining in primary NK cells as a readout for ADCC (Figure 2I, Figure S6). ADCC activity did not change between the acute and late convalescent phase (Figure 2J,

$163 \mathrm{~K})$. At both time points, 59\% - 66\% of individuals showed anti-S mediated ADCC activity.

164 However, similar to ADCP and CDC, the proportion of ADCC-mediating antibodies within the

165 fraction of anti-S antibodies increased significantly over time ( $p<0.0001$, Figure $2 \mathrm{I})$. Analyzing

166 only individuals with paired samples available, revealed similar results as the cohort as a whole

167 (Figure S3, C-H). Overall, these data show that antibody effector functions mediated by S-

168 specific antibodies remain stable over time and that the proportion of the functional antibody

169 response within the total anti-S antibodies increases over time.

172 spike and nucleocapsid protein 6-9 months after infection

173 Upon re-infection, memory B cells are rapidly activated to differentiate into antibody-producing

174 plasmablasts and/or re-initiate germinal centers in the case of secondary heterologous infection

175 with antigenically similar pathogens (38). Therefore, they may play an important role in long-

176 term immunity to SARS-CoV-2 and their evolving variants. We assessed the phenotype and

177 frequency of antigen-specific memory B cells by staining with site-specific biotinylated

178 recombinant S1 and N protein (Figure 3A, S7A, B). At late convalescence, $0.10 \%$ of the total

$179 \mathrm{CD} 27^{+} \mathrm{B}$ cells are S1-specific, whereas $0.66 \%$ are $\mathrm{N}$-specific $(\mathrm{p}<0.0001$, Figure $3 \mathrm{~B})$. (Figure

$1803 \mathrm{C}, \mathrm{D})$. The proportion of $\mathrm{CD} 27^{+} \mathrm{CD} 38^{+} \mathrm{S} 1$-specific B cells $(75 \%, \mathrm{IQR}=30 \%)$ is significantly

181 increased compared to the proportion of $\mathrm{CD} 27^{+} \mathrm{CD} 38^{+} \mathrm{N}$-specific B cells $(39 \%$, IQR $=26 \%$,

182 Mann-Whitney Test, $\mathrm{p}<0.0001$ ) (Figure 3E). Moreover, the proportion of S1-versus N-specific 
183 B cells varies within each $\mathrm{CD} 27^{+} \mathrm{B}$ cell subset $(\mathrm{p}<0.0001$, Figure $3 \mathrm{~F})$. We next analyzed S1-

184 and $\mathrm{N}$-specific B cells within the unswitched $\left(\operatorname{IgD}^{-} \operatorname{IgM}^{+}\right)$and switched $\left(\operatorname{IgD}^{-} \operatorname{IgG}{ }^{+}\right.$and $\left.\operatorname{IgD}^{-} \operatorname{Ig} \mathrm{A}^{+}\right)$

185 B cell compartments (Figure S7A). S1-specific B cells were mainly IgD'-IgG', whereas N-

186 specific B cells were either $\operatorname{IgD}^{-} \operatorname{IgM}^{+}$or $\operatorname{IgD}^{-} \operatorname{IgG}^{+}$(Figure $3 \mathrm{G}, \mathrm{H}$ ). The proportion of $\operatorname{IgD}^{-} \operatorname{IgG}^{+}$

187 S1-specific B cells $(75 \%, \mathrm{IQR}=24 \%)$ was significantly increased compared to the proportion

188 of $\operatorname{IgD}^{-} \operatorname{IgG}^{+} \mathrm{N}$-specific B cells $(37 \%, \mathrm{IQR}=17 \%)(\mathrm{p}<0.0001)$ (Figure 3I). Therefore, within each

189 switched B cell subset, the proportion of S1- versus N-specific B cells was different $(\mathrm{p}<0.0001)$

190 (Figure 3J). Taken together, SARS-CoV-2 infection induces a robust memory B cell response 191 targeting both $\mathrm{S}$ and $\mathrm{N}$.

193 SARS-CoV-2 infection induces mainly spike and membrane protein-specific memory $\mathrm{CD}^{+}$and

$194 C D 8^{+} T$ cells that are maintained up to 6-9 months after infection.

195 In addition to humoral immunity, the generation and maintenance of virus-specific cellular 196 immune responses is critical to help prevent reinfection. Long-term maintenance and 197 phenotypes of SARS-CoV-2-specific memory T cell responses are still under investigation (24, 198 39, 40). SARS-CoV-2-specific $\mathrm{CD}^{+}$and $\mathrm{CD}^{+}{ }^{+} \mathrm{T}$ cells were assessed in 33 individuals at late 199 convalescence by incubating PBMCs with peptide pools covering immunodominant sequences 200 of the viral S1, M and N protein (Figure 4A). Post incubation, activation induced marker (AIM) 201 assays identified $\mathrm{CD}^{+}$antigen-specific cells using $\mathrm{OX} 40^{+} \mathrm{CD} 137^{+}$combined with phenotypic 202 markers to measure different memory and T helper (Th) subsets (Figure S8 A-D). Percentages 203 of both S1- and M-specific $\mathrm{CD}^{+} \mathrm{T}$ cells were significantly increased compared to the 204 percentage of $\mathrm{N}$-specific cells $(\mathrm{p}<0.0001, \mathrm{p}=0.0002)$, Figure 4B). Phenotypically, $42 \%$ of virus205 specific $\mathrm{T}$ cells displayed an effector memory phenotype (CD45RA-CCR7 $\left.{ }^{+}\right)$and $87 \%$ of the 
cells showed a Th1-skewed phenotype $\left(\mathrm{CXCR}^{+} \mathrm{CCR} 6^{-}\right)$(Figure 4C, D). Comparing the

207 memory phenotype of S1-, M- and N-specific cells, we observed that a lower proportion of S1-

208 specific cells displayed an effector memory phenotype (23\%) compared to M-specific cells

$209(41 \%, \mathrm{p}=0.0457)$ and $\mathrm{N}-$-specific cells $(58 \%, \mathrm{p}<0.0001)$ (Figure S9A). Moreover, 97\% of M-

210 specific cells showed a Th1-skewed phenotype compared to only $65 \%(\mathrm{p}<0.0001)$ of the S1-

211 specific cells and $71 \%(\mathrm{p}=0.0130)$ of the $\mathrm{N}$-specific cells (Figure S9B). In eight individuals,

212 sufficient cell numbers were available to assess functionality by cytokine production after

213 peptide stimulation using a multi-parameter ex vivo intracellular cytokine staining (ICS) assay

214 (Figure S8E). SARS-CoV-2-specific CD4 ${ }^{+}$T cells produced Interleukin (IL)-2 (36\%) or IL-6

$215(28 \%)$ after peptide stimulation, and were polyfunctional (Figure 4 E, F). Percentages of IL-2

216 and $\mathrm{IL}-17^{+}$cells were significantly higher after S1 stimulation compared to $\mathrm{M}$ stimulation

$217(\mathrm{p}=0.046, \mathrm{p}=0.017)($ Figure S9C).

218 Next, we assessed the frequency and phenotype of cytotoxic CD8 ${ }^{+} \mathrm{T}$ cells by AIM assay

219 using $\mathrm{CD} 69^{+} \mathrm{CD} 137^{+}$to identify antigen-specific $\mathrm{CD}^{+} \mathrm{T}$ cells. Frequency of total SARS-CoV-

220 2-specific $\mathrm{CD}^{+}$cells is $0.44 \%$ (Figure $5 \mathrm{~A}$ ) with $61 \%$ of these SARS-CoV-2-specific CD8 ${ }^{+} \mathrm{T}$

221 cells being terminally differentiated effector memory cells (TEMRA, CD45RA ${ }^{+} \mathrm{CCR}^{-}$) (Figure

222 5B, Figure S9D). No differences were observed between S1-, M- and N-specific CD8 ${ }^{+} \mathrm{T}$ cells.

223 Similar to antigen-specific $\mathrm{CD}^{+}{ }^{+} \mathrm{T}$ cells, SARS-CoV-2-specific $\mathrm{CD}^{+} \mathrm{T}$ cells produced either

224 IL-2 (56\%) or IL-6 (16\%) after peptide stimulation, and were polyfunctional (Figure 5 C, D),

225 (Figure S9E). Interestingly, 2/33 (6\%) individuals displayed no CD4 ${ }^{+} \mathrm{T}$ cell reactivity, and 6/33

226 (19\%) individuals lacked a CD8 ${ }^{+} \mathrm{T}$ cell response after stimulation. In summary, sustained and

227 functional $\mathrm{CD}^{+}$and $\mathrm{CD}^{+} \mathrm{T}$ cell responses are detected in the study participants, even after

228 experiencing only mild or asymptomatic SARS-CoV-2 infection. These data suggest that 
229 SARS-CoV-2 can induce a long-lived cellular immune response, which could confer protection

230 after reinfection or could be reactivated with vaccination.

231 Symptomatic infection is associated with increased ADCC activity and increased frequency of

232 SARS-CoV-2-specific CD4 ${ }^{+}$T cells observed 6-9 months after infection.

233 In order to assess if symptomatic disease is associated to altered immune memory formation,

234 we compared the functional immune response between asymptomatic and symptomatic patients

235 with mild/moderate clinical presentation. Overall, no differences occurred in the humoral

236 parameters assessed in the acute phase of infection (Figure 6A, S10). At late convalescence,

237 symptomatic disease is associated with increased ADCC activity compared to asymptomatic

238 individuals $(\mathrm{p}=0.0034)$ (Figure 6A). Moreover, percentages of $\mathrm{N}$-specific CD27 ${ }^{+} \mathrm{B}$ cells, but

239 not S1-specific, were increased in asymptomatic individuals versus patients who were

240 symptomatic $(\mathrm{p}=0.051)$ (Figure 6B). Symptomatic disease was also significantly associated

241 with increased percentage of SARS-CoV-2-specific CD4 ${ }^{+} \mathrm{T}$ cells $(\mathrm{p}=0.0018)$ with a central

242 memory phenotype $(\mathrm{p}=0.0498)$ (Figure 6C, D). These data suggest that the outcome of acute

243 infection has an imprint on the memory immune response with implications for response to

244 subsequent infection or vaccination.

245 Correlations between various aspects of the functional anti-viral memory response

246 In order to assess the relation between antibody titers, functional humoral immunity, and the

247 cellular T and B cell compartment we performed extensive correlation analysis (Figure 7). Age

248 correlated to anti-S antibody titers and S1-specific CD $19^{+} \operatorname{IgD}^{-} \operatorname{IgG}^{+}$and $\mathrm{CD} 19^{+} \mathrm{CD} 27^{+} \mathrm{B}$ cells.

249 In the acute phase of infection, anti-S IgG, IgM and IgA titers, functionality, measured by

250 seroneutralization, and effector functions correlated. Seroneutralization, anti-S IgA, and ADCC

251 correlated over time, albeit not very strong. Antibody effector functions 2-9 days post 
252 laboratory confirmation negatively correlated with total antigen-specific and S1-specific CD4 ${ }^{+}$

253 T cells at late convalescence.

254 At late convalescence, anti-S IgG correlated with all three effector functions, but not 255 with neutralizing capacity. Within the B cell compartment, $\mathrm{N}$-specific $\mathrm{IgG}^{+}, \mathrm{IgA}^{+}$and $\mathrm{CD}^{+} 7^{+}$

256 B cells correlated to one another, as did S1-specific $\operatorname{IgG}^{+}, \operatorname{IgA}^{+}$and $\mathrm{CD}_{2} 7^{+} \mathrm{B}$ cells. No

257 correlation was identified between S1- and N-specific B cells. Anti-S IgG titers, ADCP, and

$258 \mathrm{CDC}$ correlated with $\mathrm{S} 1$-specific $\mathrm{IgG}^{+}$and $\mathrm{CD}^{2} 7^{+} \mathrm{B}$ cells. The $\mathrm{S} 1$-specific $\mathrm{CD}^{+} \mathrm{T}$ cell

259 responses correlated with $\mathrm{S} 1$-specific $\mathrm{CD}^{+} \mathrm{T}$ cell responses, but did not correlate to antibody

260 titers nor to effector functions or to S1-specific B cells. Overall, different aspects of a functional

261 immune memory response do not fully correlate with one another and require separate

262 evaluation when considering long-term immunity to SARS-CoV-2.

\section{Discussion}

In this study, we investigated a partially asymptomatic cohort of Cambodian individuals

266 in the acute and late convalescent phase for anti-S antibody titers, neutralization and effector

267 functions, as well as SARS-CoV-2-specific B and T cell responses. As Cambodia was relatively

268 COVID-19-free throughout 2020 (35), it is highly unlikely this cohort had additional exposure

269 events after inclusion in this study, that could have boosted their immunity to SARS-CoV-2.

270 One limitation is the uncertainty of the exact timing of exposure/infection, as infections were

271 identified by screening at entry into Cambodia rather than in a direct surveillance or community

272 cohort.

273 Studies assessing long-term immunity to SARS-CoV-2 in Asian populations are scarce

$274(16,32-34,41)$. In addition, studies on cross-reactivity of the humoral and cellular compartment 
275 with other hCoVs have mainly focused on European and US populations (42-45). Historically,

276 the population in East Asia seems to be more exposed to coronavirus-like viruses as only East

277 Asian population show genetic adaptation to coronaviruses (46). The main natural reservoir of

278 SARS-related coronaviruses is believed to be Horseshoe bats (genus Rhinolophus), which are

279 endemic to Southeast Asia and China (47-49). Whether possible cross-reactivity to other

280 coronavirus-like viruses or hCoVs may have influenced the adaptive immune response to

281 SARS-CoV-2 in Southeast Asian populations remained to be investigated.

As expected, anti-S IgM, IgG and IgA titers declined over time and anti-S IgG becomes

283 the major isotype at late convalescence $(24,50-52)$. In this study, IgA titers were the most

284 affected over time. The formation of anti-S $\operatorname{IgA}$ is shown to be dependent on local lung

285 inflammation (53-55) hence titers decline the strongest in asymptomatic/mild patients. Titers

286 of neutralizing antibodies are reported to reach their maximum within the first month after

287 infection and then decay, but mostly remain detectable six months and even up to one year after

288 infection $(10,24)$. A relatively low rate of individuals retained neutralizing antibodies at late

289 convalescence in this cohort (56\%) as most longitudinal studies found $76-98 \%$ of individuals

290 remaining positive $(19,24)$. This might be attributed to the absence of possible re-exposure

291 and/or the consequence of asymptomatic/mild infection $(10,26,39,51)$. In contrast with other

292 papers, neutralizing titers did not correlate to anti-S IgG antibodies at late convalescence. This

293 might be due to varying relative contribution of anti-S IgG, IgM and IgA to SARS-CoV-2

294 neutralization at late convalescence, the genetic background of the participants or can be due to

295 the different technique to measure anti-S binding and neutralizing antibodies $(56,57)$.

Fc-mediated effector functions contribute to clearance of virus-infected cells but are

297 often critically overlooked. SARS-CoV-2 infection induces Fc-mediated effector functions 
298 irrespective of disease outcome (19-21). Antibody effector functions develop rapidly after

299 infection and correlate with anti-S IgG and neutralizing titers in the acute phase and at late

300 convalescence $(19,20)$. In this current study, between $55-66 \%$ of individuals showed antibody

301 effector function activity up to nine months after infection. Also, ADCC persisted in a higher

302 percentage of individuals compared to neutralization or other effector functions $(22,23)$. We

303 report here the maintenance of CDC over time suggesting that both ADCC and CDC can

304 contribute to protection from re-infection. ADCP levels decreased over time which could have

305 consequences for antigen presentation and macrophage activation upon re-infection (58).

306 Interestingly, the ratio of S-mediated effector functions over total anti-S IgG increases over

307 time. Together with reports showing the evolution of the BCR repertoire over time $(26,59,60)$,

308 these data indicate ongoing affinity maturation and evolution of the antibody response to a more

309 functional response. Therefore, measurement of only S-binding antibodies at late

310 convalescence does not reflect their function.

311 S-, RBD- and N-specific memory B cells are maintained more than six months post

312 symptom onset and their frequency increased over time $(24,61,62)$. In this cohort, S1-and N-

313 specific memory B cells persisted up to 6-9 months post infection with some variability between

314 individuals. The percentage of S1-specific IgG B cells correlated with S-specific IgG

315 antibodies, and S1-specific B cells displayed an activated phenotype. This suggests that these

316 B cells could be recruited after secondary exposure with SARS-CoV-2 and might confer some

317 level of protection against infection with new variants via additional diversification trough

318 germinal center responses (38).

319 Anti-SARS-CoV-2 T cell immunity was assessed by AIM, which is a sensitive assay

320 that provides a broader picture of the overall antigen-specific $\mathrm{T}$ cell response, compared to 
321 cytokine-detection based assays $(6,63)$. Persistence of functional memory T cells after SARS-

322 CoV-2 infection has been reported, also after asymptomatic infection $(24,64)$. Similar to other

323 reports, virus-specific memory $\mathrm{CD}^{+} \mathrm{T}$ cells were skewed to a Th1 or Th1/Th17 profile and

324 displayed mainly an effector memory (CD45RA-CCR7 $\left.{ }^{-}\right)$phenotype $(27,64,65)$. Virus-specific

$325 \mathrm{CD}^{+} \mathrm{T}$ cells consisted mostly of cells with a TEMRA phenotype, a compartment of cytotoxic

$326 \mathrm{CD}^{+} \mathrm{T}$ with limited proliferative potential (66). Polyfunctional virus-specific $\mathrm{CD}^{+}$and $\mathrm{CD} 8^{+}$

327 T cells could be detected, mainly secreting IL-2 (16, 39), albeit we could only include few

328 individuals in this analysis. Similar to other long-term cohorts, virus-specific $\mathrm{CD}^{+}$and $\mathrm{CD}^{+}$

329 cells can be detected in up to $90 \%-70 \%$ of the individuals, respectively (4).

330 Differences in frequency and phenotype of $\mathrm{N}$ - and S-specific B and T cells has been

331 reported before $(24,27,39,67)$. This might be due to the difference in antigen availability,

332 persistence, and immunological context. Together with other envelope proteins, S proteins

333 cover the surface of the virus and bind to the host cell, while the $\mathrm{N}$ protein underlies viral

334 packaging and hence is less accessible (68). The $\mathrm{N}$ protein is more conserved among

335 coronaviruses (68), whereas $\mathrm{S}$ protein and especially the RBD-bearing S1 subunit are more

336 prone for acquiring mutations $(69,70)$. Consequently, anti-N IgG rather than anti-S1 IgG can

337 be found in individuals not exposed to SARS-CoV-2 $(68,71,72)$. This might explain the

338 observed higher frequency of N-specific B cells in our study.

339 Correlations between $\mathrm{CD}^{+} \mathrm{T}$ cells and humoral responses can be observed in some

340 long-term cohorts $(27,29,73,74)$ but not all (24). In this study, there was no correlation

341 between the S-specific cellular and humoral immune compartment at late convalescence.

342 Therefore, neither anti-S IgG nor neutralizing antibodies are a good proxy to determine the

343 cellular response to SARS-CoV-2. Moreover, correlations between anti-S antibody titers and 
344 Fc-related functions at late convalescence are weak and subtle differences might lead to a

345 different disease outcome upon re-exposure. Hence, serological testing alone might not be

346 sufficient to understand the full spectrum of long-term immunity generated after SARS-CoV-2

347 infection.

348 The development, characteristics and functionality of the totality of long-term immunity

349 in asymptomatic infected individuals remains to be further characterized. We observed an

350 increase of ADCC at late convalescence in patients who had mild/moderate disease compared

351 to asymptomatic individuals. This observation is in line with studies showing increased anti-S

352 IgG afucosylation in severe patients compared to mild and asymptomatic cases $(75,76)$. Indeed,

353 afucosylated monoclonal antibodies can cause elevated ADCC though increased IgG-Fc $\gamma$ RIIIa

354 affinity $(77,78)$. More severe COVID-19 induced a stronger SARS-CoV-2-specific CD4 ${ }^{+} \mathrm{T}^{\mathrm{T}}$

355 cell response (27-29). We confirm and extend these data as we observed lower levels of virus-

356 specific $\mathrm{CD}^{+} \mathrm{T}$ cells in asymptomatic individuals compared to mild/moderate cases. These

357 data suggest that different disease outcome after infection results in altered long-term immunity,

358 which could shape the response to subsequent infection or vaccination.

359 Taken together, our work shows additional evidence of long-term and persistent

360 immunity after asymptomatic and mild SARS-CoV-2 infection. Furthermore, this cohort

361 describes the immune response in individuals of Asian origin and in the absence of re-exposure

362 to SARS-CoV-2. We show the persistence of humoral immunity, antibody effector functions,

363 and virus-specific memory $\mathrm{T}$ and $\mathrm{B}$ cells 6-9 months after infection, which do not correlate to

364 each other. These data enhance our understanding of long-term functional immunity. 


\section{$367 \underline{\text { Methods }}$}

368 Study population

369 Ethical approval for the study was obtained from the National Ethics Committee of Health

370 Research of Cambodia. Written informed consent was obtained from all participants prior to

371 inclusion in the study. Pre-pandemic blood samples were obtained from clinically healthy

372 individuals included in the dengue vaccine initiative study in 2015-2016. Clinically healthy

373 adult volunteers who presented at the International Vaccination Centre, Institut Pasteur du

374 Cambodge before the onset of the pandemic were included to validate the antigen-specific B

375 and $\mathrm{T}$ cell staining. Acute SARS-CoV-2 infected patients were identified via screening of

376 imported cases in Cambodia between $6^{\text {th }}$ March to $12^{\text {th }}$ August 2020. All laboratory confirmed

377 cases are quarantined and monitored for symptoms. Moreover, 1-15 follow-up

378 nasopharyngeal/oropharyngeal swab samplings for SARS-CoV-2 detection were conducted to

379 assess viremia. Patients were only discharged after two consecutive negative RT-PCR tests

380 within 48 h. Symptomatic patients displayed mild/moderate symptoms such as running nose,

381 cough, fever and difficult to breath. In total, we included 64 individuals for follow up. In 33

382 individuals, 2-9 days after laboratory confirmation, a blood sample was obtained. A second

383 blood sample was obtained 6-9 months later from all 64 study participants. Participant

384 characteristics and clinical signs are summarized in Table S1. Plasma was collected and stored

385 at $-80^{\circ} \mathrm{C}$, The PBMCs were isolated via Ficoll-Paque separation, cryopreserved in $10 \%$

386 DMSO/FBS and stored in liquid nitrogen until analysis. The National Institute for Biological

387 Standards and Control (NIBSC) 20/130 (research reagent) and 20/118 (reference panel) have

388 been obtained from WHO Solidarity II, the global serologic study for COVID-19. 
391 Molecular detection of SARS-CoV-2 in combined nasopharyngeal/oropharyngeal swabs was

392 performed as previously described (36). Briefly, RNA was extracted with the QIAamp Viral

393 RNA Mini Kit (Qiagen) and real-time RT-PCR assays for SARS-CoV-2 RNA detection were

394 performed in using primers/probes from Charité Virologie (Berlin, Germany (79)) to detect

395 both $\mathrm{E}$ and RdRp genes.

396 Virus neutralization assay

397 The detection of neutralizing antibodies was achieved by foci reduction neutralization test 398 (FRNT) similar as described before (80) and adapted to SARS-CoV-2. Briefly, serial diluted,

399 heat-treated plasma samples were incubated with a Cambodian SARS-CoV-2 isolate (ancestral 400 strain; GISAID: EPI_ISL_956384; (36)) for $30 \mathrm{~min}$ at $37^{\circ} \mathrm{C}$ and $5 \% \mathrm{CO}_{2}$. The mixtures were 401 distributed on African green monkey kidney cells (VeroE6; ATCC CRL-1586) and incubated 402 again for $30 \mathrm{~min} 37^{\circ} \mathrm{C}$ and $5 \% \mathrm{CO}_{2}$. Afterwards, the mixtures were replaced by an overlay 403 medium containing 2\% carboxymethyl cellulose (Sigma-Aldrich) in Dulbecco's modified 404 Eagle medium (DMEM; Sigma-Aldrich) supplemented with 3\% FBS (Gibco) and 100 U/mL 405 penicillin-streptomycin (Gibco). Infection was visualized 16-18h after inoculation by staining 406 of infected cells with a SARS-CoV-2-specific antibody (rabbit, antibodies-online GmbH), 407 targeting the S2 subunit of the viral spike protein, and afterwards with antibody anti-rabbit IgG 408 HRP conjugate (goat; antibodies-online GmbH). Finally, cells were incubated with TrueBlue 409 TMB substrate (KPL), and infection events appear as stained foci and were counted with an 410 ELISPOT reader (AID Autoimmune Diagnostika GmbH, Strassberg, Germany). The amount 411 of neutralizing antibodies is expressed as the reciprocal serum dilution that induces $50 \%$ 412 reduction of infection (FRNT50) compared to the positive control (virus only) and is calculated 
413 by $\log$ probit regression analysis (SPSS for Windows, Version 16.0, SPSS Inc., Chicago, IL,

414 USA). FRNT50 titers below 10 are considered negative.

415 S-expressing cell lines

416 Transfected cell lines, Raji (ATCC® CCL-86 ${ }^{\mathrm{TM}}$ ) and 293T (ATCC® CRL-3216 ${ }^{\mathrm{TM}}$ ), with

417 SARS-Cov-2 spike plasmid or a control plasmid using Lipofectamine 2000 (Life technologies)

418 are kind gifts from Olivier Schwartz, Institut Pasteur, Paris, France (19). Spike-expressing Raji

419 cells and Raji control cells were cultured at $37^{\circ} \mathrm{C}, 5 \% \mathrm{CO} 2$ in RPMI medium while 293T-spike

420 cells and 293T control cells were cultured in DMEM medium. All media were completed with

421 10\% FBS (Gibco, MT, USA), 1\% L glutamine (Gibco), 1\% penicillin/streptomycin and

422 puromycin $\left(1 \mu \mathrm{g} / \mathrm{mL}, \mathrm{Gibo}^{\mathrm{TM}}\right)$ for cell selection during the culture.

423 S-Flow assay

424 The S-Flow assay was performed as previously described (37). Briefly, plasma samples were 425 diluted (1:200) in 1xPBS with 2mM EDTA and 0.5\% BSA (PBS/BSA/EDTA) and incubated

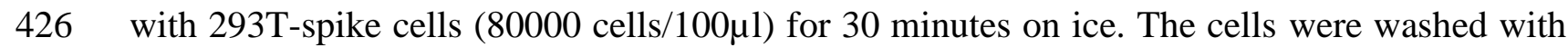

427 PBS/BSA/EDTA and stained either with anti-IgM PE (dilution 1:100, Biolegend) and anti-IgG

428 Alexa Fluor ${ }^{\mathrm{TM}} 647$ (dilution 1:600, Thermo Fisher) or anti-IgA Alexa Fluor 647 (dilution 1:800,

429 Jakson ImmunoResearch) for 30 minutes on ice. The cells were washed with 1xPBS and fixed

430 using buffer of the True-Nuclear Transcription Factor Staining kit (Biolegend). After fixing,

431 the cells were washed and resuspended in 1xPBS. The results were acquired using FACS Canto

432 II, BD Biosciences. The gating strategy for anti-IgM, anti-IgG or anti-IgA positive cells was

433 based on the 293T control cells incubated with negative SARS-CoV-2 reference plasma. The

434 data were reported as percentage of positive cells for anti-IgM, anti-IgG or anti-IgA. The

435 NIBSC Research Reagent (20/130) and panel (20/118) (WHO Solidarity II) was utilized to set 
436 the cutoff for positivity based on the background staining of the negative SARS-CoV-2 plasma

437 and calculated following formula: cut-off $=\%$ positive cells $+2 \mathrm{x}$ standard deviation.

438 Antibody dependent cellular phagocytosis (ADCP) assay

439 THP-1 cells (ATCC® TIB-202 ${ }^{\mathrm{TM}}$ ) were used as phagocytic cells. For this, $1 \mu \mathrm{g}$ of biotinylated

440 S1 protein (Genscripts) was used to saturate the binding sites on $1 \mu$ l of FluoroSphere

441 neutravidin beads (Thermo Fisher) overnight at $4^{\circ} \mathrm{C}$. Excess protein was removed by washing

442 the pelleted beads. The protein-coated beads were incubated with $40 \mu 1$ heated-inactivated

443 plasma diluted in complete RPMI (1:40) for 15 minutes at room temperature. Then, $5 \times 10^{4}$ THP-

4441 cells suspended in $50 \mu \mathrm{l}$ complete RPMI were added to the complex and incubated for 16

445 hours at $37^{\circ} \mathrm{C}, 5 \% \mathrm{CO}_{2}$. After incubation, the cells were washed with $1 \times \mathrm{xBS}$ and fixed using

446 buffer in True-Nuclear Transcription Factor Staining kit (Biolegend). After fixing, the cells

447 were washed and resuspended in 1xPBS. The samples were analyzed using FACS Canto II, BD

448 Biosciences. Phagocytosis activity was scored by the integrate mean fluorescence intensity

449 (iMFI) value (\% positive fluorescence THP-1 cells x MFI of the positive fluorescence THP-1

450 cells).

451 Complement dependent cytotoxicity $(C D C)$ assay

452 The assay used spike-expressing Raji cells as target cells, pooled serum (4 healthy donors) as

453 complement source and heated-inactivated patient plasma as antibody source. In short, $50 \mu 1$ of

454 heated-inactivated plasma (1:50) were incubated with Raji-spike cells for 30 minutes at $37^{\circ} \mathrm{C}$,

$4555 \% \mathrm{CO}_{2}$. Afterward, $50 \mu \mathrm{l}$ of complete RPMI containing $15 \%$ of pooled serum was added into

456 the cells and incubated at $37^{\circ} \mathrm{C}, 5 \% \mathrm{CO}_{2}$ for 14 hours. The cells were washed with PBS and

457 stained with Zombie Aqua viability dye (BioLegend) for 20 minutes on ice and then stained

458 anti-APC C3/C3b/iC3b antibody (Cedarlane) for 30 minutes on ice. The cells were fixed with 
fixation buffer in True-Nuclear Transcription Factor Staining kit (Biolegend) for 20 minutes on

460 ice. After fixing, the cells were washed and resuspended in 1xPBS. The samples were acquired

461 using FACS Canto II, BD Biosciences. The results were reported as percentage of cell death

462 and MFI of C3 deposition on the cells.

463 Antibody-dependent cellular cytotoxicity (ADCC) assay

464 The assay used 293T-spike cells as a target cell and purified NK cells from healthy donor

465 PMBCs as effector cells. First, 293T-spike cells were incubated with heated-inactivated patient

466 plasma diluted in complete DMEM medium (1:50) at $37^{\circ} \mathrm{C}, 5 \% \mathrm{CO}_{2}$ for 30 minutes. The NK

467 cells were enriched by magnetic negative selection (Miltenyi) according to manufactor's

468 instruction. The 293T-spike cells were washed five times with complete RPMI medium. The

469 NK cells were mixed with 293T-spike cells at a ratio 1:1 at final volume of $100 \mu$ complete

470 RPMI. Anti-CD107a and Monensin (Biolegend) 1:1000 dilution were added to the suspension

471 and incubated at $37^{\circ} \mathrm{C}, 5 \% \mathrm{CO}_{2}$ for 6 hours. The cells were washed with $1 \times \mathrm{PBS}$ and stained

472 with Zombie Aqua viability dye (BioLegend) for 20 minutes on ice. Then the cells were stained

473 with anti-CD3 and anti-CD56 for 30 minutes on ice. The cells were washed and

474 fixed/permeabilized using True-Nuclear Transcription Factor Staining kit (Biolegend) for 20

475 minutes on ice. After staining, the cells were washed and resuspended in 1xPBS. The samples

476 were acquired using FACS Canto II, BD Biosciences.

477 Detection of antigen-specific memory $B$ cells

478 Biotinylated SARS-CoV-2 S1 protein and biotinylated SARS-CoV-2 N protein were purchased

479 from GenScript. The biotinylated proteins were combined with different streptavidin (SA)

480 fluorophore conjugates, BUV496 (BD Biosciences) and PE (Biolegend), respectively, at 1:1

481 molar ratio. Briefly, each SA was added gradually (3 times, every 20 minutes) to $20 \mu 1$ of each 
482 biotinylated protein $(1 \mu \mathrm{M})$ on ice. The reaction was quenched with D-biotin (GeneCopeia) at

$48350: 1$ molar ratio to SA for a total probe volume of $30 \mu 1$ for 30 minutes on ice. Probes were

484 then used immediately for staining. Each staining used $5 \mu$ of probe. Shortly, patient PBMCs

485 was washed with 1 xPBS and stained with Zombie Aqua viability dye (BioLegend) for 10

486 minutes on ice. The cells were stained with the probes. Then the cells were washed and stained

487 with anti-IgG antibody, for 30 minutes on ice. After that, the cells were washed and stained

488 with master mix containing of anti-CD3, anti-CD19, anti-CD27, anti-CD38, anti-IgD, anti-IgM

489 and anti-IgA antibodies for 30 minutes on ice Antibodies are listed in Table S2. After staining,

490 the cells were washed and resuspended in 1xPBS with $2 \%$ FBS. The samples were analyzed

491 using FACS Aria, BD Biosciences. The flow cytometry gating strategy to classify memory B

492 cell subsets and switched B cells is shown in Figure S7. Overall, 40 samples were of sufficient

493 quality and were included in the analysis.

494 Activation-induced markers (AIM) T cell assay

495 Antigen-specific $\mathrm{CD}^{+}$and $\mathrm{CD}^{+} \mathrm{T}$ cells, as well as memory $\mathrm{T}$ cells and $\mathrm{T}$ helper subsets were

496 assessed by Activation-Induced Marker (AIM) assay (6, 24). Cells were cultured at $37^{\circ} \mathrm{C}, 5 \%$

$497 \mathrm{CO}_{2}$, in the presence of SARS-CoV-2-specific S1, $\mathrm{M}$ and $\mathrm{N}$ protein pools $[1 \mu \mathrm{g} / \mathrm{mL}]$

498 (PepTivator® SARS-CoV-2 regents; Miltenyi Biotec) in 96-well U-bottom plates at 0,5-1x106

499 PBMCs per well. After 24 hours, cells were washed in 1xPBS supplemented with $0.5 \%$ bovine

500 serum albumin (BSA) and 2 mM EDTA (FACS buffer) and stained with Zombie Aqua Fixable

501 Viability kit (Biolegend) and incubated for $20 \mathrm{~min}$ at $4^{\circ} \mathrm{C}$ followed by surface staining for 30

$502 \mathrm{~min}$ at $4^{\circ} \mathrm{C}$. Stained cells were washed and resuspended in FACS buffer and analyzed using a

503 FACSAria Fusion (BD Biosciences). Antibodies are listed in Table S2. Negative controls

504 without peptide stimulation were included for each donor. Antigen-specific $\mathrm{CD}^{+}$and $\mathrm{CD} 8^{+} \mathrm{T}$ 
505 cells were measured subtracting the background (unstimulated control) from the peptide-

506 stimulated sample. Negative results were set to zero. Data were analyzed with FlowJo software

507 version 10.7.1 (FlowJo LLC). Overall, 33 samples were of sufficient quality and were included

508 in the analysis.

$509 \quad$ Intracellular staining (ICS) assay

510 Functional SARS-CoV-2-specific $\mathrm{CD}^{+}$and $\mathrm{CD}^{+} \mathrm{T}$ cells were assessed by surface and 511 intracellular staining in a subset of individuals if sufficient amount of PBMCs were obtained $512(\mathrm{n}=8)$. Cells were cultured at $37^{\circ} \mathrm{C}, 5 \% \mathrm{CO} 2$, in the presence of SARS-CoV-2-specific S1, M 513 and $\mathrm{N}$ protein pools separately [1 $\mu \mathrm{g} / \mathrm{mL}$ each] (PepTivator® SARS-CoV-2 reagents; Miltenyi

514 Biotec), Monensin (Biolegend) 1:1000 dilution and anti-Human CD28/CD49d purified [100 $515 \mu \mathrm{g} / \mathrm{mL}$ ] (BD Bioscience) in 96-well U-bottom plates at 0,5-1x106 PBMCs per well. After 6 516 hours, cells were washed in FACS buffer and stained using a Zombie Aqua Fixable Viability 517 kit (Biolegend) and incubated for 20 minutes at $4{ }^{\circ} \mathrm{C}$. Cells were then washed in PBS and 518 fixed/permeabilized with True-Nuclear ${ }^{\mathrm{TM}}$ Transcription Factor Buffer Set (Biolegend). Surface

519 (CD3, CD4 and CD8) and intracellular markers (IFN- $\gamma$, IL-2, IL-4, IL-6 and IL-17) were 520 detected via the subsequent addition of directly conjugated antibodies incubating for 30 minutes 521 at $4^{\circ} \mathrm{C}$. Antibodies are listed in Table S2. Stained cells were finally washed and resuspended in 522 FACS buffer and analyzed using a FACSAria Fusion (BD Biosciences). Antigen-specific CD4 ${ }^{+}$ 523 and $\mathrm{CD}^{+} \mathrm{T}$ cells were measured subtracting the background (unstimulated control) from the 524 peptide-stimulated sample. Negative results were set to zero. Data were analyzed with FlowJo 525 software version 10.7.1 (FlowJo LLC).

526 Statistical analysis 
527 Calculations, figures and statistics were made using Prism 9 (GraphPad Software) or RStudio

528 (Version 1.2.1335). The data were tested for statistical normality before applying the

529 appropriate statistical tests. All information about sample sizes and statistical tests performed

530 were shown in the figure legends. Spearman correlation plot was calculated and visualized with

531 the following packages: FactoMineR, factoextra (https://cran.r-project.org/web/

532 packages/factoextra/index.html) and corrplot (https://github.com/taiyun/corrplot) in R (Version

$533 \quad 3.6 .1)$ and RStudio (Version 1.2.1335).

534 Data availability

535 All data associated with this study are available in the main text or the supplementary materials.

537 References

538 1. Zhu N, Zhang D, Wang W, Li X, Yang B, Song J, et al. A Novel Coronavirus from

539 Patients with Pneumonia in China, 2019. N Engl J Med. 2020;382(8):727-33.

540 2. Chen N, Zhou M, Dong X, Qu J, Gong F, Han Y, et al. Epidemiological and clinical

541 characteristics of 99 cases of 2019 novel coronavirus pneumonia in Wuhan, China: a

542 descriptive study. Lancet. 2020;395(10223):507-13.

543 3. Guan WJ, Ni ZY, Hu Y, Liang WH, Ou CQ, He JX, et al. Clinical Characteristics of

544 Coronavirus Disease 2019 in China. N Engl J Med. 2020.

545 4. Sette A, Crotty S. Adaptive immunity to SARS-CoV-2 and COVID-19. Cell.

$546 \quad 2021 ; 184(4): 861-80$.

547 5. Wang M-Y, Zhao R, Gao L-J, Gao X-F, Wang D-P, Cao J-M. SARS-CoV-2:

548 Structure, Biology, and Structure-Based Therapeutics Development. Frontiers in Cellular and

549 Infection Microbiology. 2020;10:724.

$550 \quad 6 . \quad$ Grifoni A, Weiskopf D, Ramirez SI, Mateus J, Dan JM, Moderbacher CR, et al.

551 Targets of T Cell Responses to SARS-CoV-2 Coronavirus in Humans with COVID-19

552 Disease and Unexposed Individuals. Cell. 2020;181(7):1489-501.e15.

5537 7. Yoshida S, Ono C, Hayashi H, Fukumoto S, Shiraishi S, Tomono K, et al. SARS-

554 CoV-2-induced humoral immunity through B cell epitope analysis in COVID-19 infected

555 individuals. Scientific Reports. 2021;11(1):5934.

$556 \quad 8 . \quad$ Wang Q, Zhang Y, Wu L, Niu S, Song C, Zhang Z, et al. Structural and Functional

557 Basis of SARS-CoV-2 Entry by Using Human ACE2. Cell. 2020;181(4):894-904.e9.

558 9. Yan R, Zhang Y, Li Y, Xia L, Guo Y, Zhou Q. Structural basis for the recognition of

559 SARS-CoV-2 by full-length human ACE2. Science. 2020;367(6485):1444-8. 
560 10. Dispinseri S, Secchi M, Pirillo MF, Tolazzi M, Borghi M, Brigatti C, et al.

561 Neutralizing antibody responses to SARS-CoV-2 in symptomatic COVID-19 is persistent and 562 critical for survival. Nature Communications. 2021;12(1):2670.

563 11. Wajnberg A, Amanat F, Firpo A, Altman DR, Bailey MJ, Mansour M, et al. Robust

564 neutralizing antibodies to SARS-CoV-2 infection persist for months. Science.

$5652020 ; 370(6521): 1227$.

566 12. Legros V, Denolly S, Vogrig M, Boson B, Siret E, Rigaill J, et al. A longitudinal study

567 of SARS-CoV-2-infected patients reveals a high correlation between neutralizing antibodies

568 and COVID-19 severity. Cellular \& Molecular Immunology. 2021;18(2):318-27.

569 13. Yu J, Tostanoski LH, Peter L, Mercado NB, McMahan K, Mahrokhian SH, et al. DNA

570 vaccine protection against SARS-CoV-2 in rhesus macaques. Science. 2020;369(6505):806-

57111.

572 14. Schäfer A, Muecksch F, Lorenzi JCC, Leist SR, Cipolla M, Bournazos S, et al.

573 Antibody potency, effector function, and combinations in protection and therapy for SARS-

574 CoV-2 infection in vivo. J Exp Med. 2021;218(3).

575 15. Capetti AF, Borgonovo F, Mileto D, Gagliardi G, Mariani C, Lupo A, et al. One-year

576 durability of anti-spike IgG to SARS-CoV-2: preliminary data from the AntiCROWN prospective observational study One year durability of COVID-19 anti-spike IgG. J Infect. 2021.

16. Kang CK, Kim M, Lee S, Kim G, Choe PG, Park WB, et al. Longitudinal Analysis of Human Memory T-Cell Response according to the Severity of Illness up to 8 Months after SARS-CoV-2 Infection. J Infect Dis. 2021. 17. Wang Z, Muecksch F, Schaefer-Babajew D, Finkin S, Viant C, Gaebler C, et al. Naturally enhanced neutralizing breadth against SARS-CoV-2 one year after infection.

585 18. Bournazos S, Ravetch JV. Fc $\gamma$ Receptor Function and the Design of Vaccination Strategies. Immunity. 2017;47(2):224-33.

19. Dufloo J, Grzelak L, Staropoli I, Madec Y, Tondeur L, Anna F, et al. Asymptomatic and symptomatic SARS-CoV-2 infections elicit polyfunctional antibodies. Cell Rep Med. 2021;2(5):100275.

590 20. Natarajan H, Crowley AR, Butler SE, Xu S, Weiner JA, Bloch EM, et al. Markers of Polyfunctional SARS-CoV-2 Antibodies in Convalescent Plasma. mBio. 2021;12(2). 21. Zohar T, Loos C, Fischinger S, Atyeo C, Wang C, Slein MD, et al. Compromised Humoral Functional Evolution Tracks with SARS-CoV-2 Mortality. Cell. 2020;183(6):150819.e12.

595 22. Anand SP, Prévost J, Nayrac M, Beaudoin-Bussières G, Benlarbi M, Gasser R, et al. 596 Longitudinal analysis of humoral immunity against SARS-CoV-2 Spike in convalescent 597 individuals up to eight months post-symptom onset. Cell Rep Med. 2021:100290.

598 23. Lee WS, Selva KJ, Davis SK, Wines BD, Reynaldi A, Esterbauer R, et al. Decay of 599 Fc-dependent antibody functions after mild to moderate COVID-19. Cell Rep Med.

$600 \quad 2021: 100296$.

601 24. Dan JM, Mateus J, Kato Y, Hastie KM, Yu ED, Faliti CE, et al. Immunological 602 memory to SARS-CoV-2 assessed for up to 8 months after infection. Science.

$6032021 ; 371(6529)$. 
604

25. Bonifacius A, Tischer-Zimmermann S, Dragon AC, Gussarow D, Vogel A, Krettek U, et al. COVID-19 immune signatures reveal stable antiviral $\mathrm{T}$ cell function despite declining humoral responses. Immunity. 2021;54(2):340-54.e6.

26. Gaebler C, Wang Z, Lorenzi JCC, Muecksch F, Finkin S, Tokuyama M, et al. Evolution of antibody immunity to SARS-CoV-2. Nature. 2021;591(7851):639-44. 27. Zuo J, Dowell AC, Pearce H, Verma K, Long HM, Begum J, et al. Robust SARSCoV-2-specific T cell immunity is maintained at 6 months following primary infection. Nat Immunol. 2021;22(5):620-6.

28. Wheatley AK, Juno JA, Wang JJ, Selva KJ, Reynaldi A, Tan HX, et al. Evolution of immune responses to SARS-CoV-2 in mild-moderate COVID-19. Nat Commun. 2021;12(1):1162.

29. Peluso MJ, Deitchman AN, Torres L, Iyer NS, Munter SE, Nixon CC, et al. Longterm SARS-CoV-2-specific immune and inflammatory responses in individuals recovering from COVID-19 with and without post-acute symptoms. Cell Reports. 2021;36(6):109518. 30. Le Bert N, Tan AT, Kunasegaran K, Tham CYL, Hafezi M, Chia A, et al. SARSCoV-2-specific T cell immunity in cases of COVID-19 and SARS, and uninfected controls. Nature. 2020;584(7821):457-62.

31. Sariol A, Perlman S. Lessons for COVID-19 Immunity from Other Coronavirus Infections. Immunity. 2020;53(2):248-63.

32. Noh JY, Kwak J-E, Yang J-S, Hwang SY, Yoon JG, Seong H, et al. Longitudinal assessment of anti-SARS-CoV-2 immune responses for six months based on the clinical severity of COVID-19. The Journal of Infectious Diseases. 2021.

33. Ravichandran S, Lee Y, Grubbs G, Coyle EM, Klenow L, Akasaka O, et al. Longitudinal antibody repertoire in "mild" versus "severe" COVID-19 patients reveals immune markers associated with disease severity and resolution. Sci Adv. 2021;7(10). 34. Long Q-X, Jia Y-J, Wang X, Deng H-J, Cao X-X, Yuan J, et al. Immune memory in convalescent patients with asymptomatic or mild COVID-19. Cell Discovery. 2021;7(1):18. 35. WHO. COVID-19 Situation reports. 2021 [Available from: https://www.who.int/cambodia/emergencies/covid-19-response-in-cambodia/situation-reports. 36. Auerswald H, Yann S, Dul S, In S, Dussart P, Martin NJ, et al. Assessment of inactivation procedures for SARS-CoV-2. J Gen Virol. 2021;102(3).

37. Grzelak L, Temmam S, Planchais C, Demeret C, Tondeur L, Huon C, et al. A comparison of four serological assays for detecting anti-SARS-CoV-2 antibodies in human serum samples from different populations. Sci Transl Med. 2020;12(559).

38. Mesin L, Schiepers A, Ersching J, Barbulescu A, Cavazzoni CB, Angelini A, et al. Restricted Clonality and Limited Germinal Center Reentry Characterize Memory B Cell Reactivation by Boosting. Cell. 2020;180(1):92-106.e11.

39. Rodda LB, Netland J, Shehata L, Pruner KB, Morawski PA, Thouvenel CD, et al. Functional SARS-CoV-2-Specific Immune Memory Persists after Mild COVID-19. Cell. 2021;184(1):169-83.e17.

40. Peng Y, Mentzer AJ, Liu G, Yao X, Yin Z, Dong D, et al. Broad and strong memory CD4+ and CD8+ T cells induced by SARS-CoV-2 in UK convalescent individuals following COVID-19. Nature Immunology. 2020;21(11):1336-45.

41. Chia WN, Zhu F, Ong SWX, Young BE, Fong SW, Le Bert N, et al. Dynamics of SARS-CoV-2 neutralising antibody responses and duration of immunity: a longitudinal study. Lancet Microbe. 2021;2(6):e240-e9. 
42. Yang F, Nielsen SCA, Hoh RA, Röltgen K, Wirz OF, Haraguchi E, et al. Shared B cell memory to coronaviruses and other pathogens varies in human age groups and tissues. Science. 2021;372(6543):738-41.

653 43. Ogbe A, Kronsteiner B, Skelly DT, Pace M, Brown A, Adland E, et al. T cell assays differentiate clinical and subclinical SARS-CoV-2 infections from cross-reactive antiviral responses. Nat Commun. 2021;12(1):2055. analysis of immunodominance and cross-reactivity of the CD4 T cell response to SARS-CoV2. Science. 2021. 45. da Silva Antunes R, Pallikkuth S, Williams E, Esther DY, Mateus J, Quiambao L, et al. Differential $\mathrm{T}$ cell reactivity to endemic coronaviruses and SARS-CoV-2 in community and health care workers. J Infect Dis. 2021.

46. Zeberg H, Pääbo S. The major genetic risk factor for severe COVID-19 is inherited from Neanderthals. Nature. 2020;587(7835):610-2.

47. Zhou P, Yang X-L, Wang X-G, Hu B, Zhang L, Zhang W, et al. A pneumonia outbreak associated with a new coronavirus of probable bat origin. Nature. 2020;579(7798):270-3.

48. Wacharapluesadee S, Tan CW, Maneeorn P, Duengkae P, Zhu F, Joyjinda Y, et al. Evidence for SARS-CoV-2 related coronaviruses circulating in bats and pangolins in Southeast Asia.

49. Hul V, Delaune D, Karlsson EA, Hassanin A, Tey PO, Baidaliuk A, et al. A novel SARS-CoV-2 related coronavirus in bats from Cambodia. bioRxiv. 2021:2021.01.26.428212. 50. Van Elslande J, Gruwier L, Godderis L, Vermeersch P. Estimated half-life of SARSCoV-2 anti-spike antibodies more than double the half-life of anti-nucleocapsid antibodies in healthcare workers. Clin Infect Dis. 2021.

51. Harrington WE, Trakhimets O, Andrade DV, Dambrauskas N, Raappana A, Jiang Y, et al. Rapid decline of neutralizing antibodies is associated with decay of IgM in adults recovered from mild COVID-19. Cell Rep Med. 2021;2(4):100253.

52. Souilmi Y, Lauterbur ME, Tobler R, Huber CD, Johar AS, Moradi SV, et al. An ancient viral epidemic involving host coronavirus interacting genes more than 20,000 years ago in East Asia. Curr Biol. 2021.

53. Sherina N, Piralla A, Du L, Wan H, Kumagai-Braesch M, Andréll J, et al. Persistence of SARS-CoV-2-specific B and T cell responses in convalescent COVID-19 patients 68 months after the infection. Med (N Y). 2021;2(3):281-95.e4.

54. Guo L, Ren L, Yang S, Xiao M, Chang D, Yang F, et al. Profiling Early Humoral Response to Diagnose Novel Coronavirus Disease (COVID-19). Clin Infect Dis. 2020;71(15):778-85.

55. Cervia C, Nilsson J, Zurbuchen Y, Valaperti A, Schreiner J, Wolfensberger A, et al. Systemic and mucosal antibody responses specific to SARS-CoV-2 during mild versus severe COVID-19. J Allergy Clin Immunol. 2021;147(2):545-57.e9.

56. Sterlin D, Mathian A, Miyara M, Mohr A, Anna F, Claër L, et al. IgA dominates the early neutralizing antibody response to SARS-CoV-2. Sci Transl Med. 2021;13(577). 57. Gasser R, Cloutier M, Prévost J, Fink C, Ducas É, Ding S, et al. Major role of IgM in the neutralizing activity of convalescent plasma against SARS-CoV-2. Cell Reports. 2021;34(9):108790. 
695

58. Tay MZ, Wiehe K, Pollara J. Antibody-Dependent Cellular Phagocytosis in Antiviral Immune Responses. Frontiers in Immunology. 2019;10(332).

59. Sakharkar M, Rappazzo CG, Wieland-Alter WF, Hsieh CL, Wrapp D, Esterman ES, et al. Prolonged evolution of the human B cell response to SARS-CoV-2 infection. Sci Immunol. 2021;6(56).

60. Dugan HL, Stamper CT, Li L, Changrob S, Asby NW, Halfmann PJ, et al. Profiling B cell immunodominance after SARS-CoV-2 infection reveals antibody evolution to nonneutralizing viral targets. Immunity. 2021;54(6):1290-303.e7.

61. Robbiani DF, Gaebler C, Muecksch F, Lorenzi JCC, Wang Z, Cho A, et al. Convergent antibody responses to SARS-CoV-2 in convalescent individuals. Nature. 2020;584(7821):437-42.

62. Kreer C, Zehner M, Weber T, Ercanoglu MS, Gieselmann L, Rohde C, et al. Longitudinal Isolation of Potent Near-Germline SARS-CoV-2-Neutralizing Antibodies from COVID-19 Patients. Cell. 2020;182(4):843-54.e12.

63. Reiss S, Baxter AE, Cirelli KM, Dan JM, Morou A, Daigneault A, et al. Comparative analysis of activation induced marker (AIM) assays for sensitive identification of antigenspecific CD4 T cells. PLoS One. 2017;12(10):e0186998.

64. Sekine T, Perez-Potti A, Rivera-Ballesteros O, Strålin K, Gorin JB, Olsson A, et al. Robust T Cell Immunity in Convalescent Individuals with Asymptomatic or Mild COVID-19. Cell. 2020;183(1):158-68.e14.

65. Cohen KW, Linderman SL, Moodie Z, Czartoski J, Lai L, Mantus G, et al. Longitudinal analysis shows durable and broad immune memory after SARS-CoV-2 infection with persisting antibody responses and memory B and T cells. Cell Reports Medicine. 2021;2(7).

66. Willinger T, Freeman T, Hasegawa H, McMichael AJ, Callan MF. Molecular signatures distinguish human central memory from effector memory CD8 T cell subsets. J Immunol. 2005;175(9):5895-903.

67. Hartley GE, Edwards ESJ, Aui PM, Varese N, Stojanovic S, McMahon J, et al. Rapid generation of durable B cell memory to SARS-CoV-2 spike and nucleocapsid proteins in COVID-19 and convalescence. Sci Immunol. 2020;5(54).

68. Cubuk J, Alston JJ, Incicco JJ, Singh S, Stuchell-Brereton MD, Ward MD, et al. The SARS-CoV-2 nucleocapsid protein is dynamic, disordered, and phase separates with RNA. Nature Communications. 2021;12(1):1936.

69. Laha S, Chakraborty J, Das S, Manna SK, Biswas S, Chatterjee R. Characterizations of SARS-CoV-2 mutational profile, spike protein stability and viral transmission. Infection, Genetics and Evolution. 2020;85:104445.

70. Korber B, Fischer WM, Gnanakaran S, Yoon H, Theiler J, Abfalterer W, et al. Tracking Changes in SARS-CoV-2 Spike: Evidence that D614G Increases Infectivity of the COVID-19 Virus. Cell. 2020;182(4):812-27.e19.

71. Ng KW, Faulkner N, Cornish GH, Rosa A, Harvey R, Hussain S, et al. Preexisting and de novo humoral immunity to SARS-CoV-2 in humans. Science. 2020;370(6522):1339.

72. Song G, He W-t, Callaghan S, Anzanello F, Huang D, Ricketts J, et al. Cross-reactive serum and memory B-cell responses to spike protein in SARS-CoV-2 and endemic coronavirus infection. Nature Communications. 2021;12(1):2938. 
73. Bartsch YC, Fischinger S, Siddiqui SM, Chen Z, Yu J, Gebre M, et al. Discrete

SARS-CoV-2 antibody titers track with functional humoral stability. Nature Communications. 2021;12(1):1018.

74. Pušnik J, Richter E, Schulte B, Dolscheid-Pommerich R, Bode C, Putensen C, et al. Memory B cells targeting SARS-CoV-2 spike protein and their dependence on CD4(+) T cell help. Cell Rep. 2021:109320.

75. Chakraborty S, Gonzalez J, Edwards K, Mallajosyula V, Buzzanco AS, Sherwood R, et al. Proinflammatory IgG Fc structures in patients with severe COVID-19. Nature Immunology. 2021;22(1):67-73. Afucosylated IgG characterizes enveloped viral responses and correlates with COVID-19 severity. Science. 2021;371(6532). human IgG1 N-linked oligosaccharide improves binding to human Fcgamma RIII and antibody-dependent cellular toxicity. J Biol Chem. 2002;277(30):26733-40. Afucosylated anti-cancer antibodies with enhanced antibody-dependent cellular cytotoxicity. MAbs. 2018;10(5):693-711.

79. Corman VM, Landt O, Kaiser M, Molenkamp R, Meijer A, Chu DK, et al. Detection of 2019 novel coronavirus (2019-nCoV) by real-time RT-PCR. Euro surveillance : bulletin Europeen sur les maladies transmissibles $=$ European communicable disease bulletin . 2020;25(3):2000045.

763

\section{$\underline{\text { Acknowledgements }}$}

This publication has been supported by WHO Solidarity II, global serologic study for COVID-

767 19, with funding from the German Federal Ministry of Health (BMG) COVID-19 Research and

768 development to WHO. We would like to acknowledge all patients that participated to the study.

769 We would like to thank Borita Heng for her technical assistance.

770 The study was funded by the Howard Hughes Medical Institute (HHMI)-Wellcome Trust

771 (208710/Z/17/Z to T.C.), and « URGENCE COVID-19 » fundraising campaign of Institut

772 Pasteur (T.C., H.A.,P.D.). H.A. is supported by the German Centre for International Migration

773 and Development (CIM). The graphical abstract was created with BioRender.com 
775 Conceptualization: TC, PD, EAK; Methodology: HV, AM, HA, LS, SS, NY, PP; Investigation:

776 HV, AM, HA, BT, DV, TC, EAK; Visualisation: HV, AM, HA, SL; Funding acquisition: TC,

777 HA, PD; Patient inclusion: HS, SS; Cohort management and patient selection: SL, SL; Project

778 administration: TC, EAK, PP, PD; Supervision: HV, AM, BT, SO, DV, EAK, TC; Writing,

779 original draft: HV, AM, HA, TB, EAK, TC; Writing, review and editing: HV, AM, HA, TB,

780 VD, OS, EAK, TC

781 Competing interests

782 The authors declare no competing interests

\section{Supplemental information}

784 Fig. S1. Characterization of the cohort

785 Fig. S2. Measurement of anti-S-binding antibodies using S-Flow

786 Fig. S3. Analysis of antibody features in paired patient samples

787 Fig. S4. Antibody-dependent cellular phagocytosis (ADCP) assay

788 Fig. S5. Complement-dependent cytotoxicity (CDC) assay

789 Fig. S6. Antibody-dependent cellular cytotoxicity (ADCC) assay

790 Fig. S7. Representative gating strategy used to define antigen-specific B cells

791 Fig. S8. Representative gating strategy used for the T cells assays

792 Fig. S9. Characterization of SARS-CoV-2-specific T Cells

793 Fig. S10. Comparison of immune parameters in asymptomatic and symptomatic individuals

794 Table S1. Cohort Description

795 Table S2. Monoclonal antibody list 
bioRxiv preprint doi: https://doi.org/10.1101/2021.08.12.455901; this version posted August 12, 2021. The copyright holder for this preprint (which was not certified by peer review) is the author/funder, who has granted bioRxiv a license to display the preprint in perpetuity. It is made available under aCC-BY-ND 4.0 International license.

A
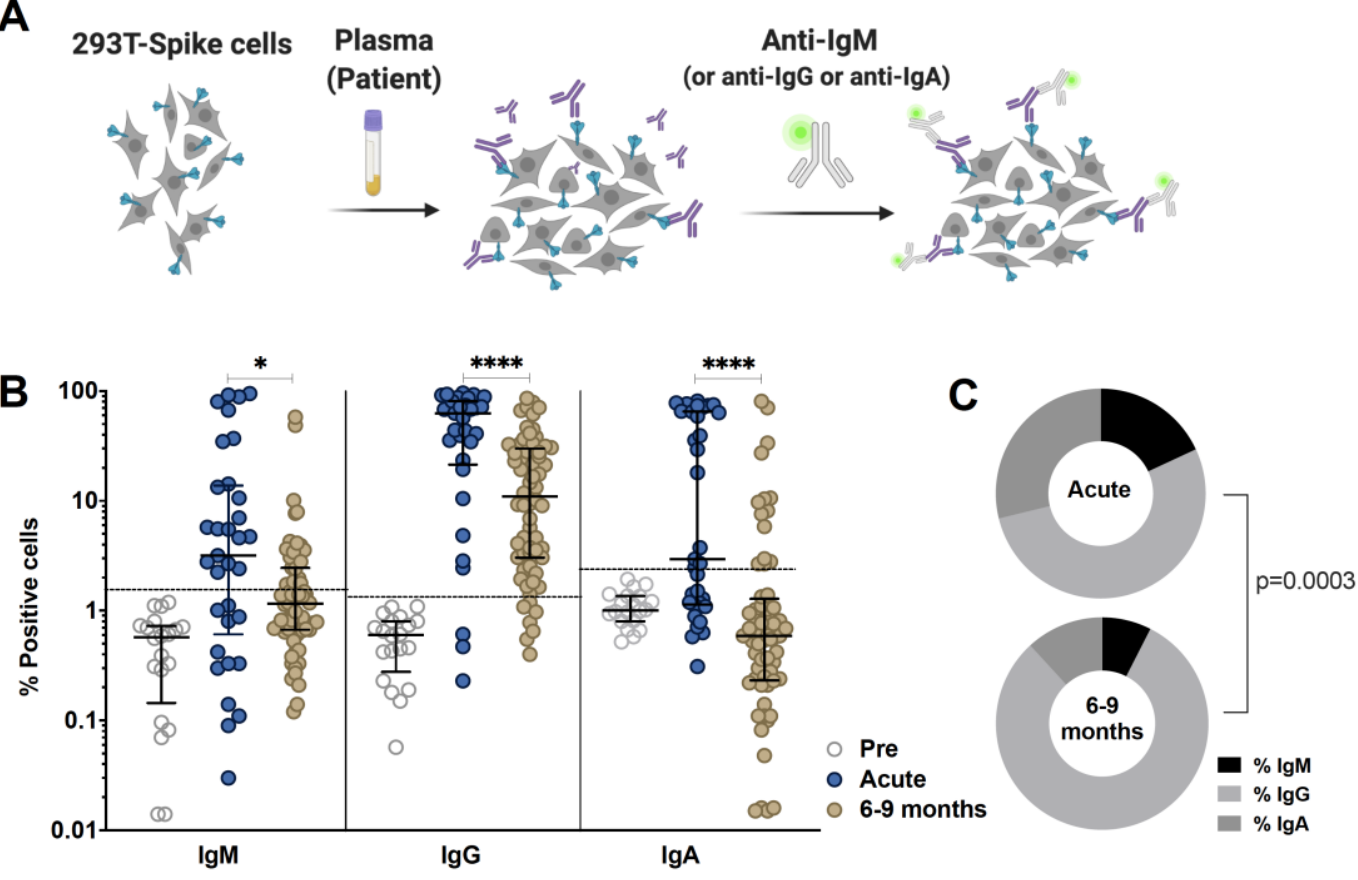

D

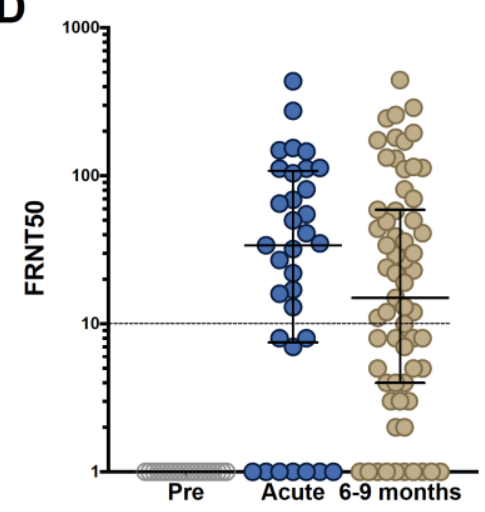

E

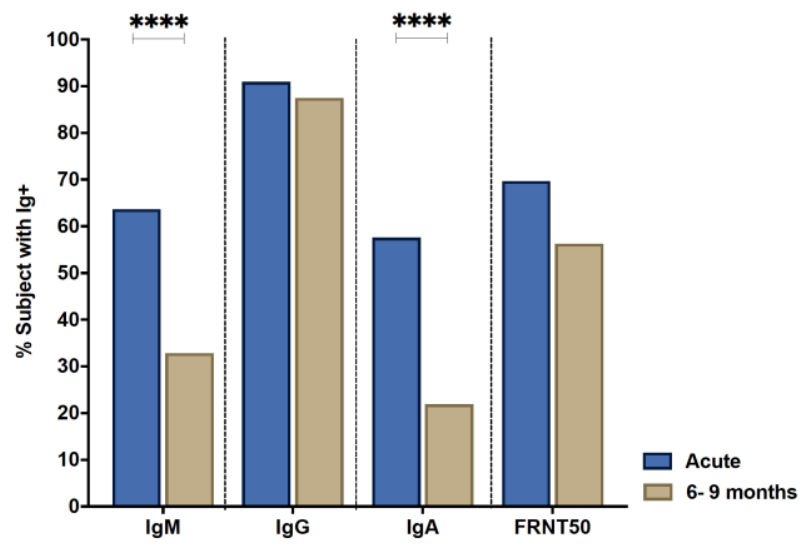


799 Figure 1. Comparison of antibody response in SARS-CoV-2-infected individuals during

800 the acute phase and 6-9 months post infection. Individuals were sampled 2-9 days post

801 laboratory confirmation and 6-9 months later. (A) Schematic model of the S-Flow assay. (B)

802 Amount of antibodies against spike protein were reported as percentage of spike-expressing

803 293T cells bound by IgM, IgG, IgA in the S-Flow assay. (C) Pie charts show the proportion of

804 anti-S IgM, IgG and IgA antibodies. (D) SARS-CoV-2 neutralizing activity was calculated as

805 FRNT50 titer in foci reduction neutralization test (FRNT). (E) Comparison of the percentage

806 of individuals positive for anti-S IgM, IgG, IgA and FRNT50. Statistical comparisons were

807 performed by Mann Whitney test (B and D) and Chi-square test (C and E). The dashed line

808 indicates the cutoff for positivity based on values calculated following formula: cut-off $=\%$

809 mean positive cells from 19 pre-pandemic samples $+3 \mathrm{x}$ standard deviation. Each dot represents

810 the result from a single individual. Lines represent median and IQR. ${ }^{*} p<0.05, * * p<0.01$,

$811 * * * \mathrm{p}<0.001$, and $* * * * \mathrm{p}<0.0001$. Pre-pandemic $\mathrm{n}=19$, acute $\mathrm{n}=33,6-9$ months $\mathrm{n}=64$. 


\section{Antibody-dependent cellular phagocytosis (ADCP)}

\section{A}

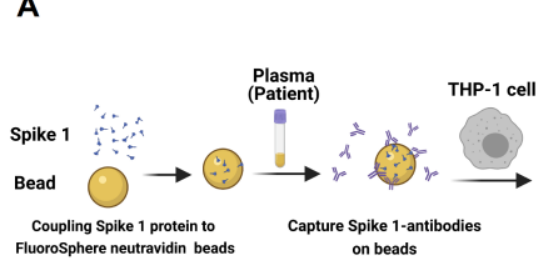

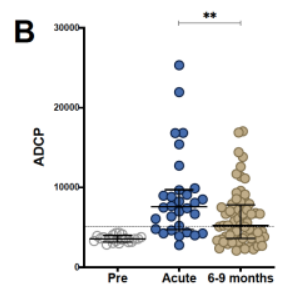
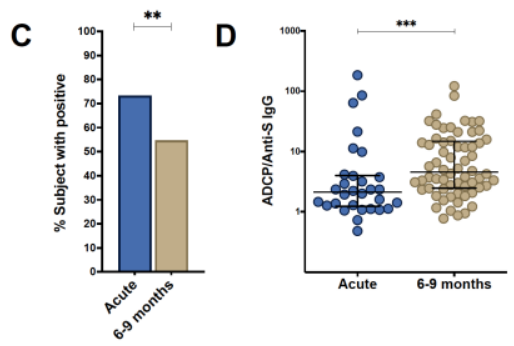

Complement-dependent cytotoxicity (CDC)

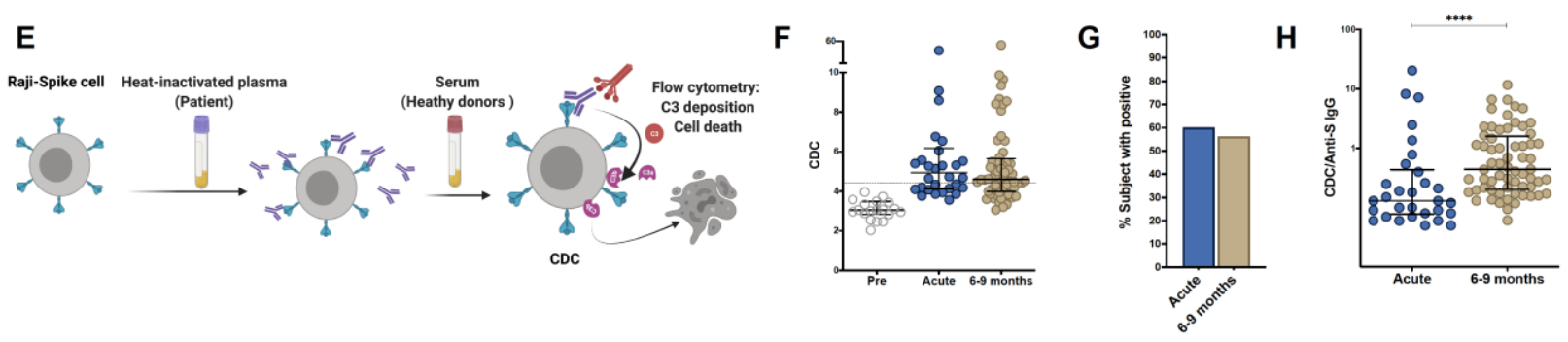

Antibody-dependent cellular cytotoxicity (ADCC)

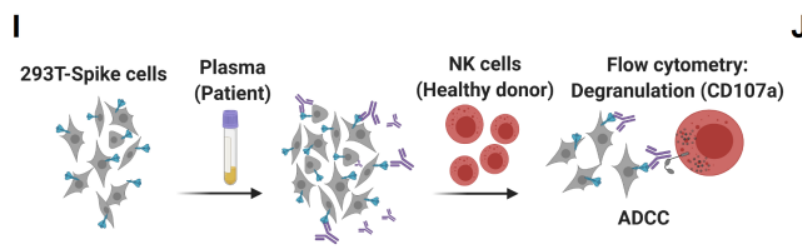

812

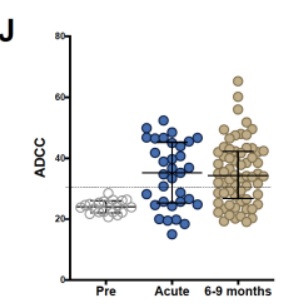

L

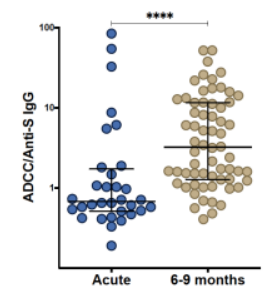


813 Figure 2. Comparison of effector function profiles of plasma from SARS-CoV-2-infected

814 individuals during the acute phase and 6-9 months post infection. Individuals were sampled

815 2-9 days post laboratory confirmation and 6-9 months later. (A) Schematic representation of

816 the antibody-dependent cellular phagocytosis (ADCP) assay. (B) Comparison of ADCP activity

817 in pre-pandemic samples, SARS-CoV-2-infected individuals in the acute phase of infection and

818 6-9 months later. (C) Ratio of ADCP to anti-spike IgG measured by S-Flow. (D) Schematic

819 representation of complement-dependent cytotoxicity (CDC) assay. (E) Comparison of CDC

820 activity in pre-pandemic samples, SARS-CoV-2-infected individuals in the acute phase of

821 infection and 6-9 months later. (F) Ratio of CDC to anti-spike IgG as measured by S-Flow. (G)

822 Schematic representation of antibody-dependent cellular cytotoxicity (ADCC). SARS-CoV-2

823 plasma induced NK degranulation as measured by CD107a staining using spike-expressing

$824293 \mathrm{~T}$ cells as target cells. NK cells were isolated from healthy donors. (H) Comparison of

825 ADCC activity in pre-pandemic samples, SARS-CoV-2-infected individuals in the acute phase

826 of infection and 6-9 months later. (I) Ratio of ADCC to anti-spike IgG as measured by S-Flow.

827 Statistical comparisons were performed by Mann Whitney test. The dashed line indicates the

828 cutoff for positivity set based on values calculated following formula: cut-off $=\%$ mean positive

829 cells from 19 pre-pandemic samples $+3 x$ standard deviation. Each dot represents result from a

830 single individual. Lines represent median and IQR.**p $<0.01$, ***p $<0.001$, and $* * * * p<$

831 0.0001. Pre-pandemic $n=19$, acute $n=33,6-9$ months $n=64$. 
bioRxiv preprint doi: https://doi.org/10.1101/2021.08.12.455901; this version posted August 12, 2021. The copyright holder for this preprint (which was not certified by peer review) is the author/funder, who has granted bioRxiv a license to display the preprint in perpetuity. It is made available under aCC-BY-ND 4.0 International license.

A

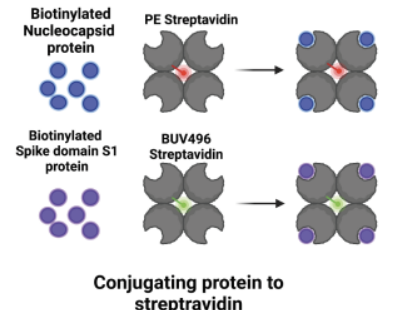
streptravidin

C
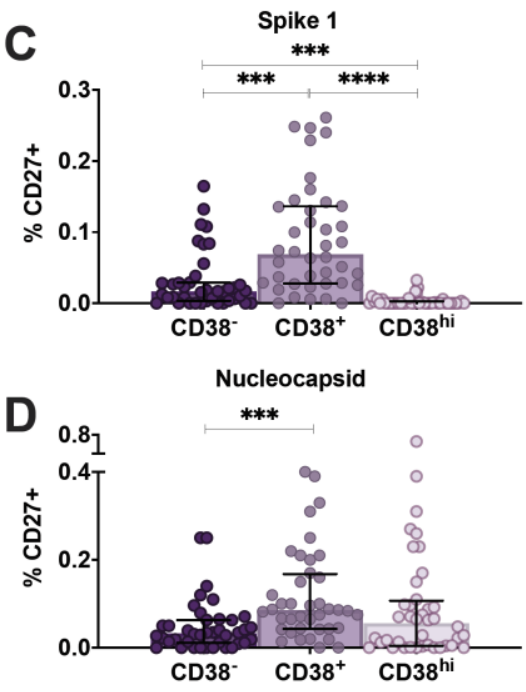

G

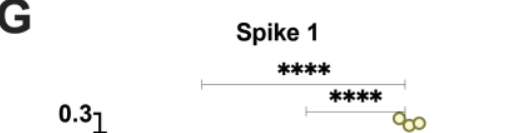

832
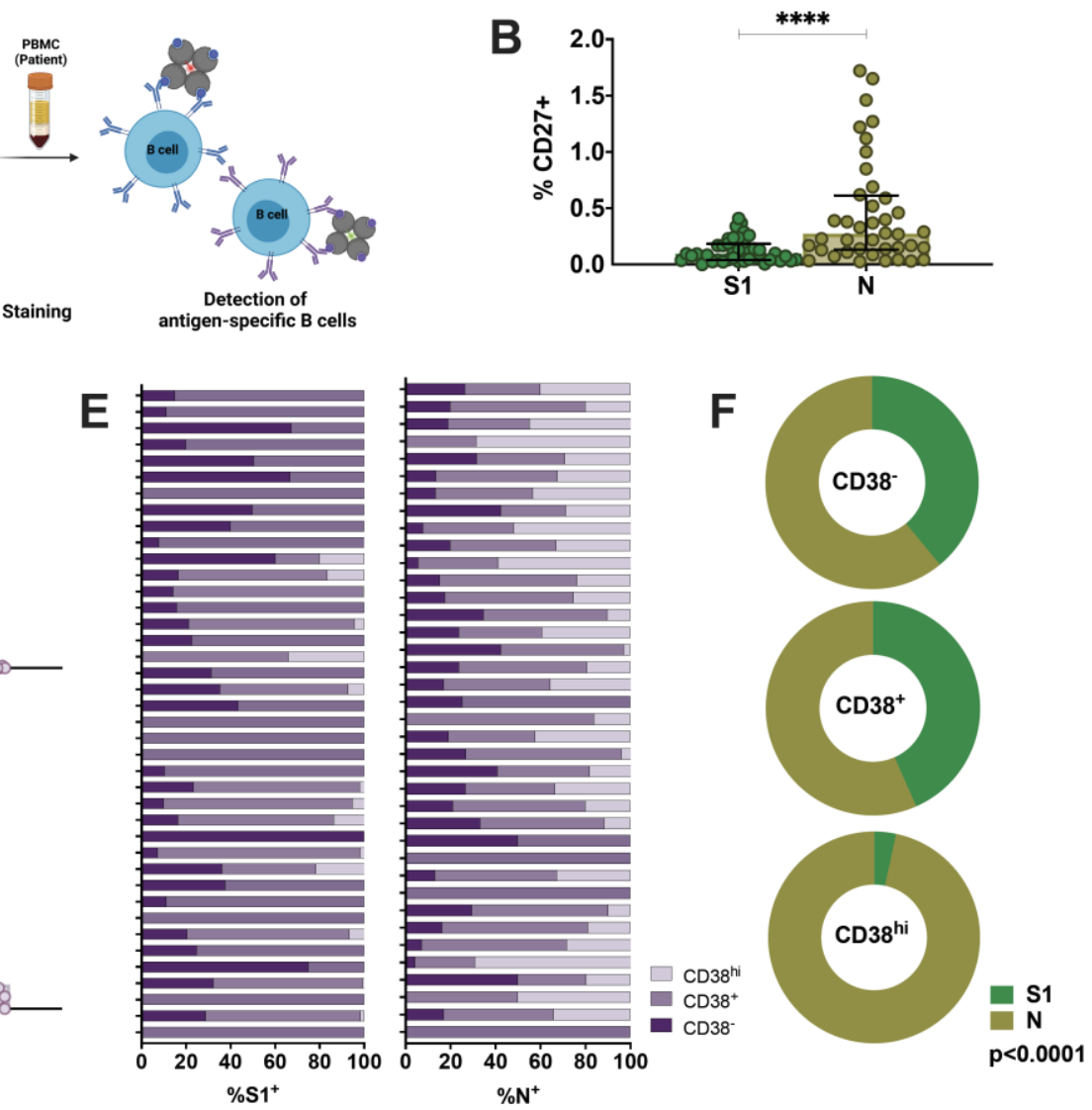

I
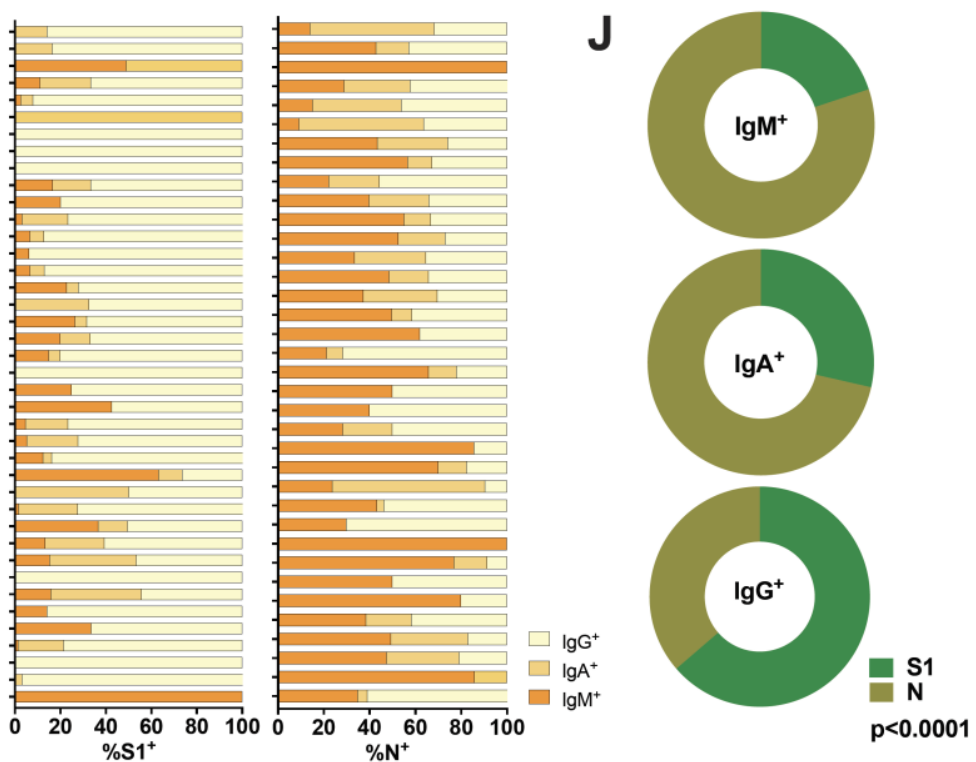
833 Figure 3. Characterization of antigen-specific memory B cells in the peripheral blood of

834 individuals infected with SARS-CoV-2 6-9 months after infection.

835 (A) Schematic representation of the memory B cell assay. (B) Comparison of percentages of

836 S1-specific or N-specific memory B cells $\left(\mathrm{CD} 19^{+} \mathrm{CD} 27^{+}\right) .(\mathbf{C}, \mathbf{D})$ Percentages of S1- and N-

837 specific B cells among resting memory B cells $\left(\mathrm{CD} 38^{-}\right)$, activated memory B cells $\left(\mathrm{CD} 38^{+}\right)$or

838 plasmablasts within the $\mathrm{CD} 27^{+}$memory B cell population. (E, F) Proportion of S1-specific and

839 N-specific $\mathrm{CD} 27^{+} \mathrm{CD} 19^{+} \mathrm{B}$ cell subsets for each individual and the whole cohort $(\mathbf{G}, \mathbf{H})$

840 Percentages of $\mathrm{S} 1-$ and N-specific cells in non-class-switched B cells $\left(\operatorname{IgD}^{-} \operatorname{IgM}^{+}\right)$or class-

841 switched B cells $\left(\operatorname{IgD}^{-} \operatorname{IgA}^{+}\right.$or $\left.\operatorname{IgD}^{-} \operatorname{IgG}^{+}\right)$. (I, J) Proportion of S1-specific and N-specific

842 switched and unswitched CD19 ${ }^{+}$B cells for each individual and for the whole cohort. Statistical

843 comparisons were performed by Mann-Whitney test (B), Wilcoxon Rank Sum test (C, D, G, H)

844 or Chi-square test (F, J). The dashed line indicates the cutoff for positivity set based on values

845 calculated following formula: cut-off $=\%$ mean positive cells from 19 pre-pandemic samples

$846+3 \mathrm{x}$ standard deviation. Each dot represents result from a single individual $(\mathrm{n}=40)$. Lines

847 represent median and IQR. $\quad * * \mathrm{p}<0.01, * * * \mathrm{p}<0.001$, and $* * * * \mathrm{p}<0.0001 . \mathrm{n}=40$. S1: subunit

8481 of spike protein, N: Nucleocapsid protein. 
A

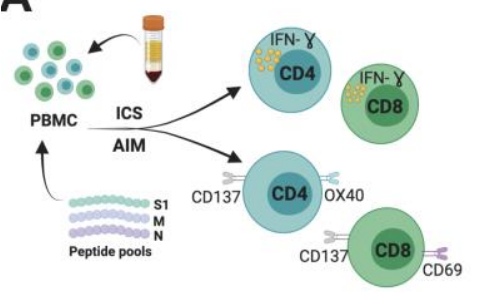

B

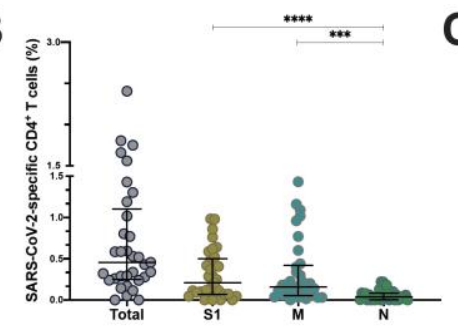

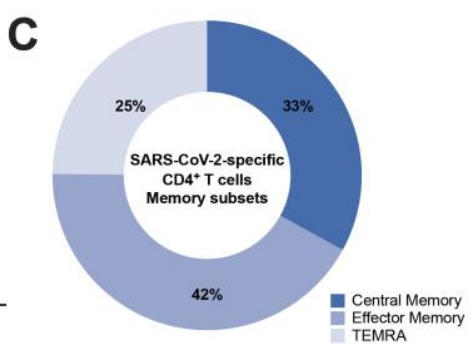

E

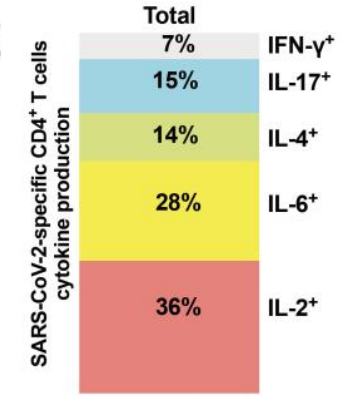

F

SARS-CoV-2-specific

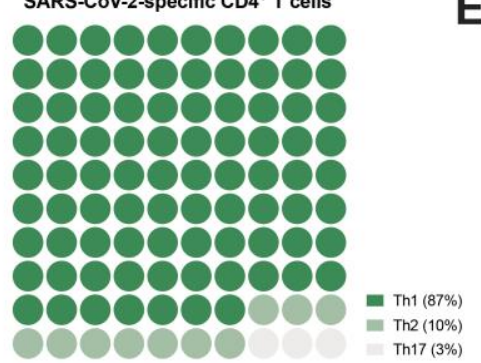

Figure 4. SARS-CoV-2-specific CD4 ${ }^{+} \mathbf{T}$ cells 6-9 months post-infection. (A) Schematic

representation of the $\mathrm{CD} 4^{+} \mathrm{T}$ cell assay $(\mathbf{B})$ Frequency (percentage of $\mathrm{CD} 4^{+} \mathrm{T}$ cells) of total

SARS-CoV-2-specific CD4 ${ }^{+} \mathrm{T}$ cells after overnight stimulation with $\mathrm{S}, \mathrm{M}$ and $\mathrm{N}$ peptide pools as assessed by induced expression of OX40 and CD137. Each dot represents result from a single individual $(\mathrm{n}=8)$. Lines represent median and IQR, $\mathrm{n}=33$ (B) Distribution of SARS-CoV-2-

855 specific $\mathrm{CD}^{+} \mathrm{T}$ cells among central memory, effector memory, and terminally differentiated 856 effector memory cells (TEMRA). (C) Frequencies of SARS-CoV-2-specific CD4 ${ }^{+} \mathrm{T}$ helper

857 (Th) subset. (D) Cytokine production and (E) pie chart representing the multifunctional SARS-

$858 \mathrm{CoV}$-2-specific $\mathrm{CD}^{+} \mathrm{T}$ cell response assessed by intracellular cytokine staining after

859 incubation with SARS-CoV-2 peptides compared to unstimulated control. Statistical

860 comparisons were performed by Kruskal-Wallis test (B) and Wilcoxon Rank Sum test (F). p<

$8610.05,{ }^{* *} \mathrm{p}<0.01,{ }^{* * *} \mathrm{p}<0.001, * * * * \mathrm{p}<0.0001$. S1: subunit 1 of spike protein; M: membrane

862 protein; N: nucleocapsid protein. 

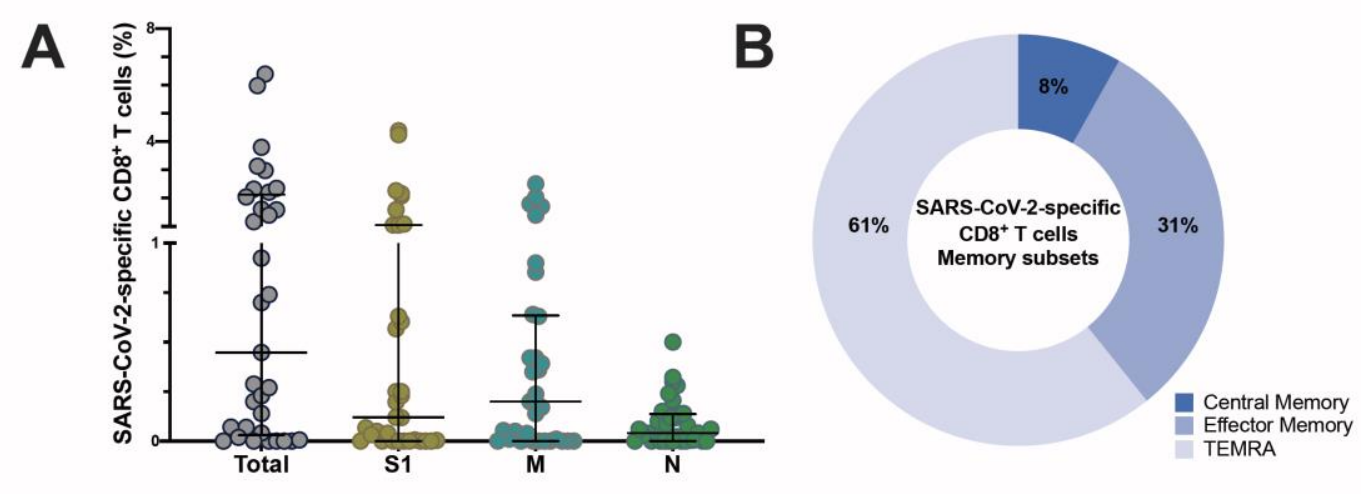

864 Figure 5. SARS-CoV-2-specific CD8 $^{+}$T cells 6-9 months post-infection. (A) Frequency

865 (percentage of $\mathrm{CD}^{+} \mathrm{T}$ cells) of total SARS-CoV-2-specific CD8 ${ }^{+} \mathrm{T}$ cells after overnight

866 stimulation with S, M and N peptide pools as assessed by induced expression of CD69 and

867 CD137. Each dot represents result of a single individual $(n=33)$. Lines represent median and

$868 \mathrm{IQR}, \mathrm{n}=33$. (B) Distribution of SARS-CoV-2-specific CD8 ${ }^{+} \mathrm{T}$ cells among central memory,

869 effector memory, and terminally differentiated effector memory cells (TEMRA). (C) Cytokine

870 production and (D) pie chart representing the multifunctional CD8 ${ }^{+} \mathrm{T}$ of SARS-Cov-2-specific

871 T cells assessed by intracellular cytokine staining after incubation with SARS-CoV-2 peptides

872 compared to unstimulated control. Statistical comparisons were performed by (A) Kruskal-

873 Wallis test and (D) Wilcoxon Rank Sum test. $* p<0.05, * * p<0.01, * * * p<0.001$. S1: subunit

8741 of spike protein; M: membrane protein; N: nucleocapsid protein. 

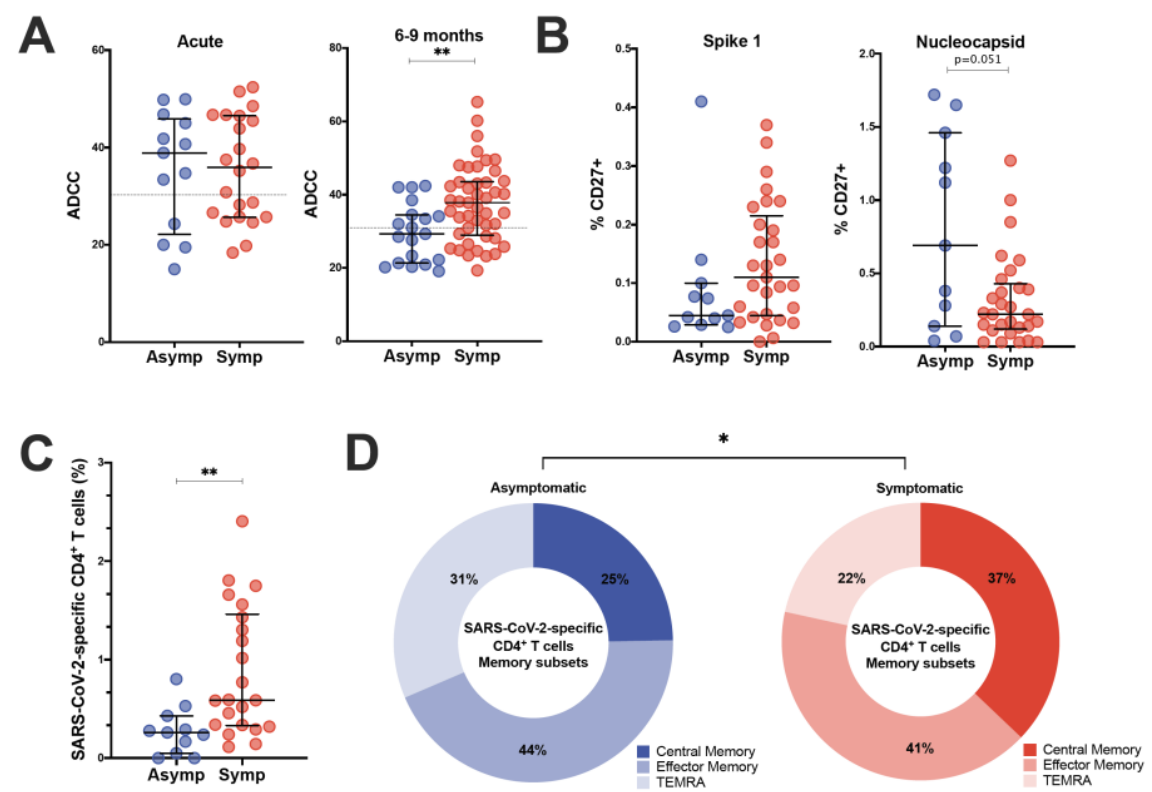

876 Figure 6. Comparison of adaptive immunity in asymptomatic and symptomatic

877 individuals. (A). Comparisons of ADCC activity in asymptomatic (asymp; $\mathrm{n}=12$ ) versus

878 symptomatic (symp; $\mathrm{n}=20$ ) individuals in the acute phase and 6-9 months after confirmed 879 infection using 293T-spike cells as target cell. Percentage of CD107a positive cells is measured

880 as readout for ADCC. (B) Comparison of percentages of S1-specific or N-specific memory B 881 cells $\left(\mathrm{CD} 19^{+} \mathrm{CD} 27^{+}\right)$between 11 asymptomatic individuals and 29 symptomatic individuals. 882 (C) Frequency (percentage of $\mathrm{CD}^{+}{ }^{+} \mathrm{T}$ cells) of total SARS-CoV-2-specific $\mathrm{CD}^{+}{ }^{+} \mathrm{T}$ cells after 883 overnight stimulation with peptide pools comparing asymptomatic individuals (asymp; $\mathrm{n}=11$ ) 884 with symptomatic patients (symp; $\mathrm{n}=22$ ). (D) Comparison of $\mathrm{CD}^{+} \mathrm{T}$ cell memory phenotype 885 between asymptomatic individuals (asymp; $\mathrm{n}=11$ ) and symptomatic patients (symp; $\mathrm{n}=22$ ).

886 Statistical comparisons were performed by (A, B and C) Mann Whitney tests and (D) Chi887 square test for trend $* \mathrm{p}<0.05, * *_{\mathrm{p}}<0.01$. 


\section{A}

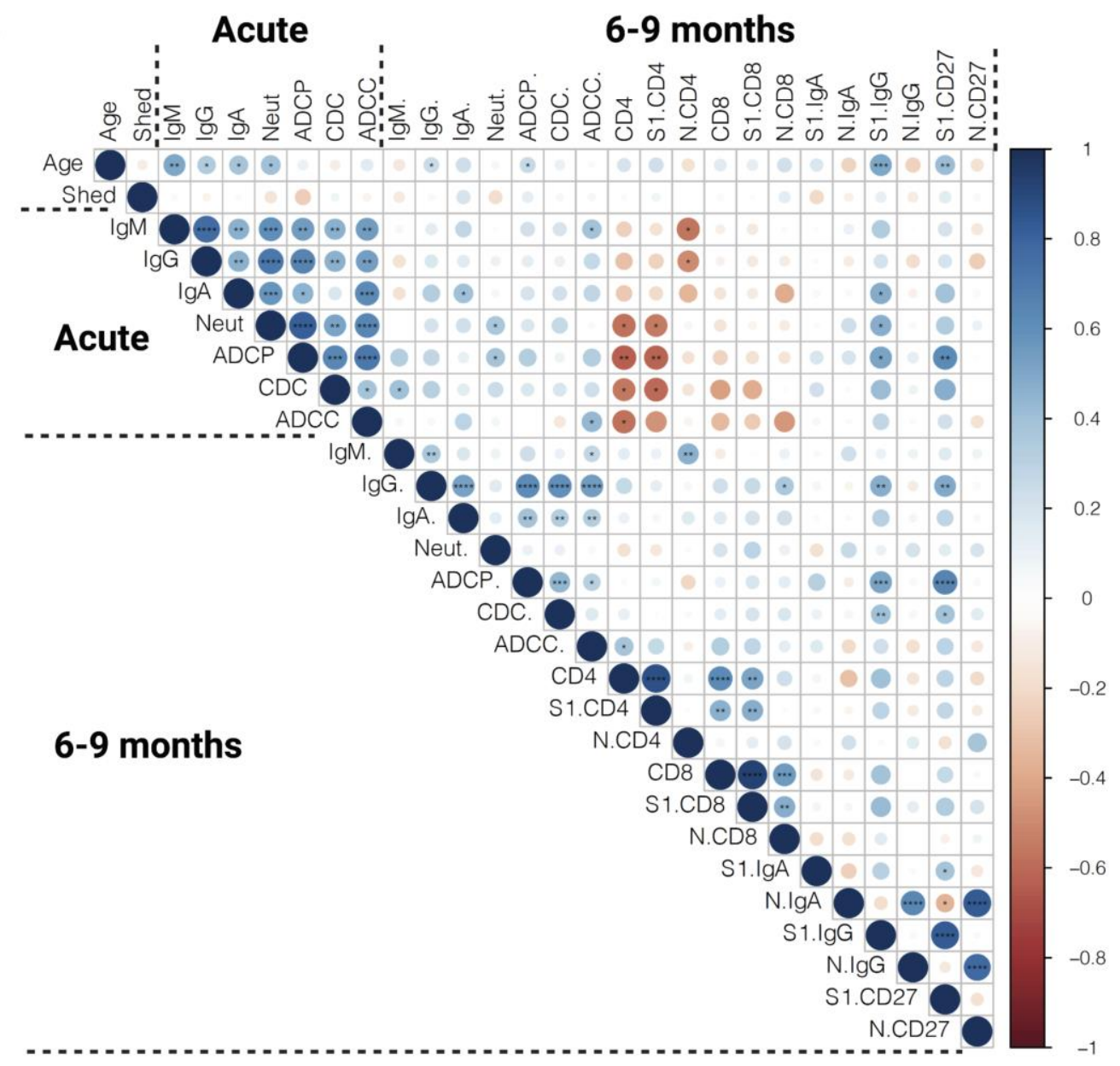

Figure 7. Spearman correlation matrix. Humoral immunity and effector functions measured

890 in the acute phase and 6-9 months post infection were correlated to each other and to frequencies

891 of antigen-specific B and T cells measured 6-9 months after infection. Red represents a negative

892 correlation between two variables and blue indicates a positive correlation. The size of the dot

893 represents the magnitude of the correlation coefficient. Statistical analysis was performed with

894 spearman correlation test. $* \mathrm{p}<0.05, * * \mathrm{p}<0.01, * * * \mathrm{p}<0.001, * * * * \mathrm{p}<0.001$. 


\section{Supplementary Material}

A

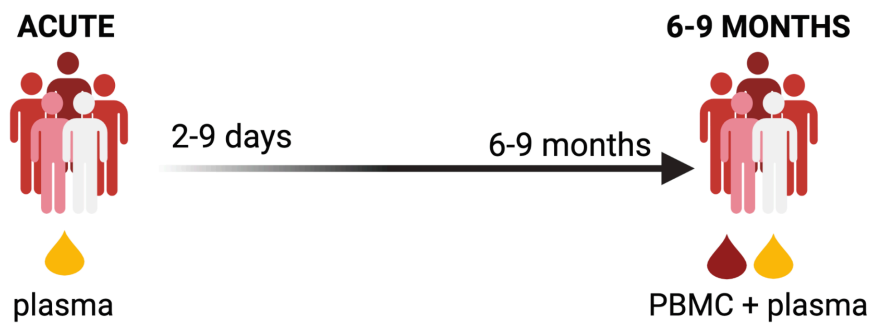

\begin{tabular}{|c|c|c|}
\hline Humoral Immunity & Humoral Immunity & Cellular Immunity \\
S-flow \\
virus neutralization \\
Effector functions
\end{tabular}

B

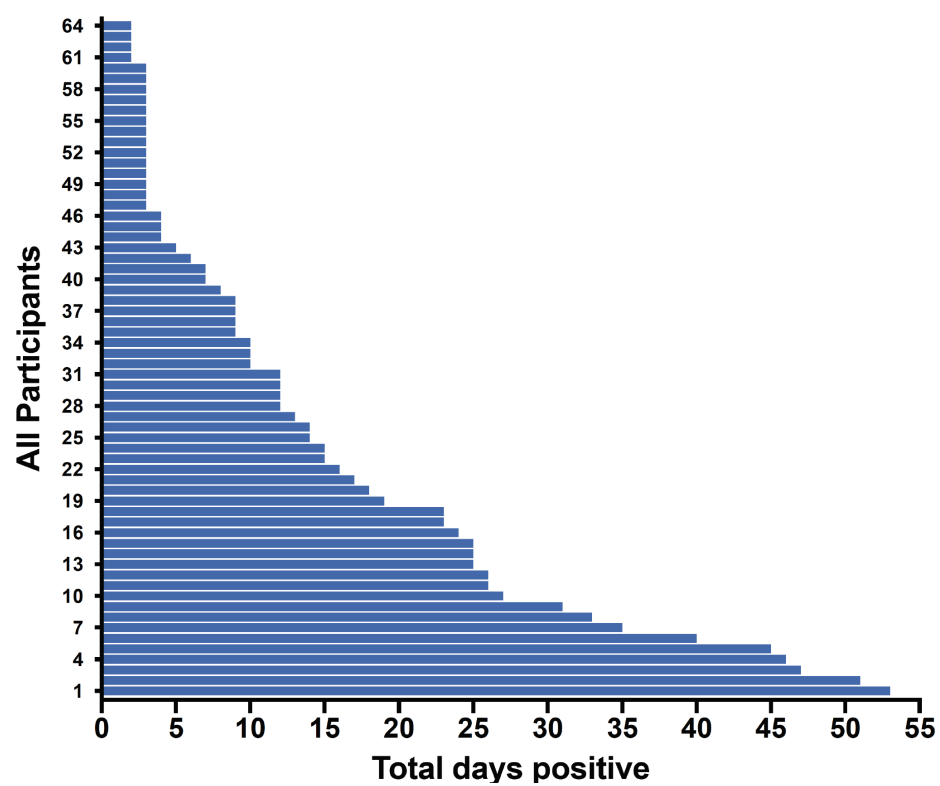

3 Figure S1. Characterization of the cohort

4 (A) Graphical summary of the assays performed on samples of the different time points. (B)

5 Length of RNA shedding in the patients. 
A
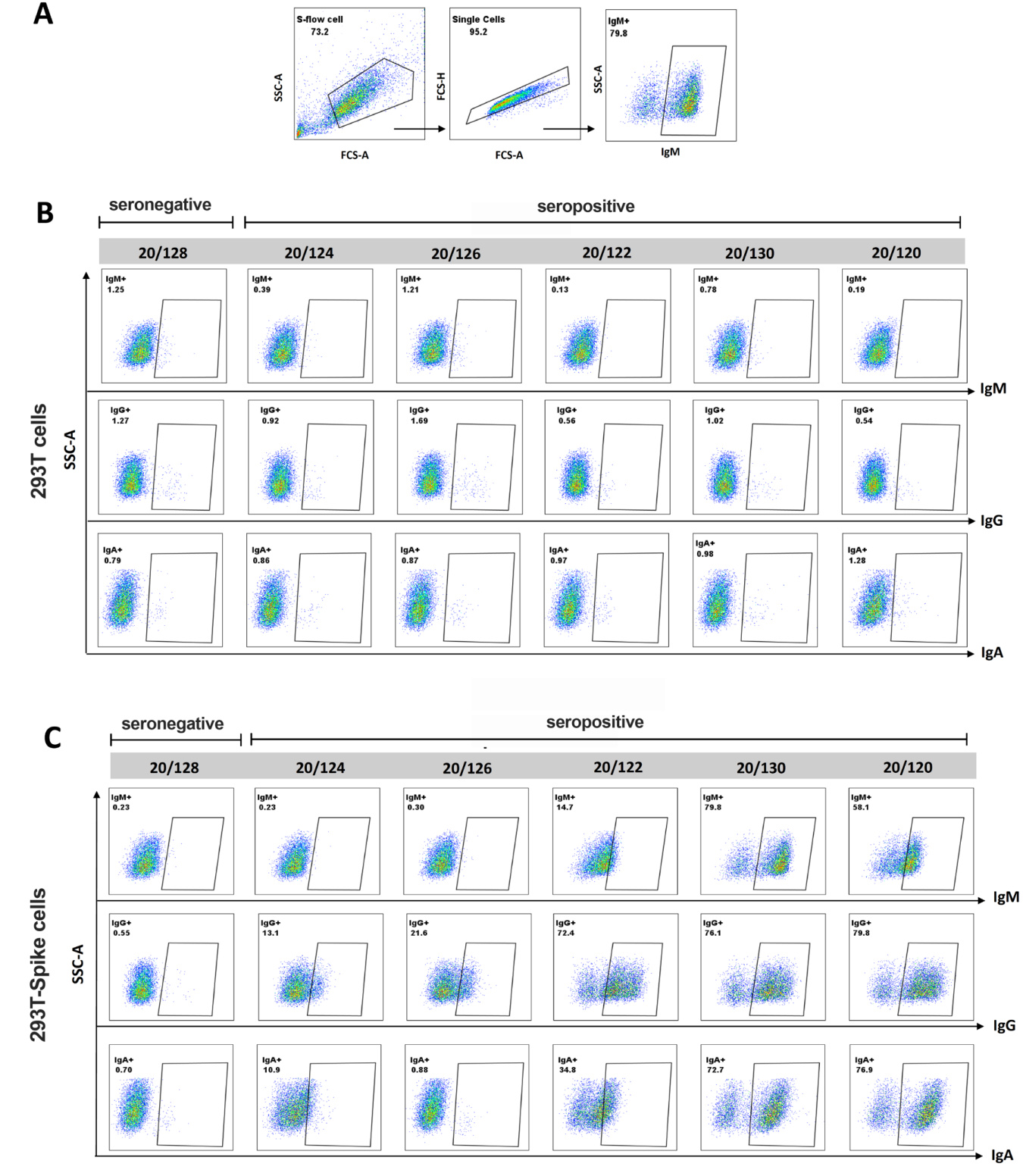

7 Figure S2. Measurement of anti-S-binding antibodies using S-Flow.

8 (A) Representative gating strategy (B-C) Percentages of spike-binding Ig were measured in

9 plasma as percentage of cells, which are positive for anti-IgM, anti-IgG or anti-IgA. Specific

10 binding was calculated as $100 \times$ (\% binding on S-expressing 293T cells - \% binding on 293T

11 control cells $) /(100-\%$ of binding to $293 \mathrm{~T}$ control cells $)$. Graph shows data from triplicate testing

12 of the COVID-19 reference plasma panel (NIBSC 20/120, 20/124, 20/124, 20/126, 20/128,

$1320 / 130$ ) obtained from the NIBSC. 

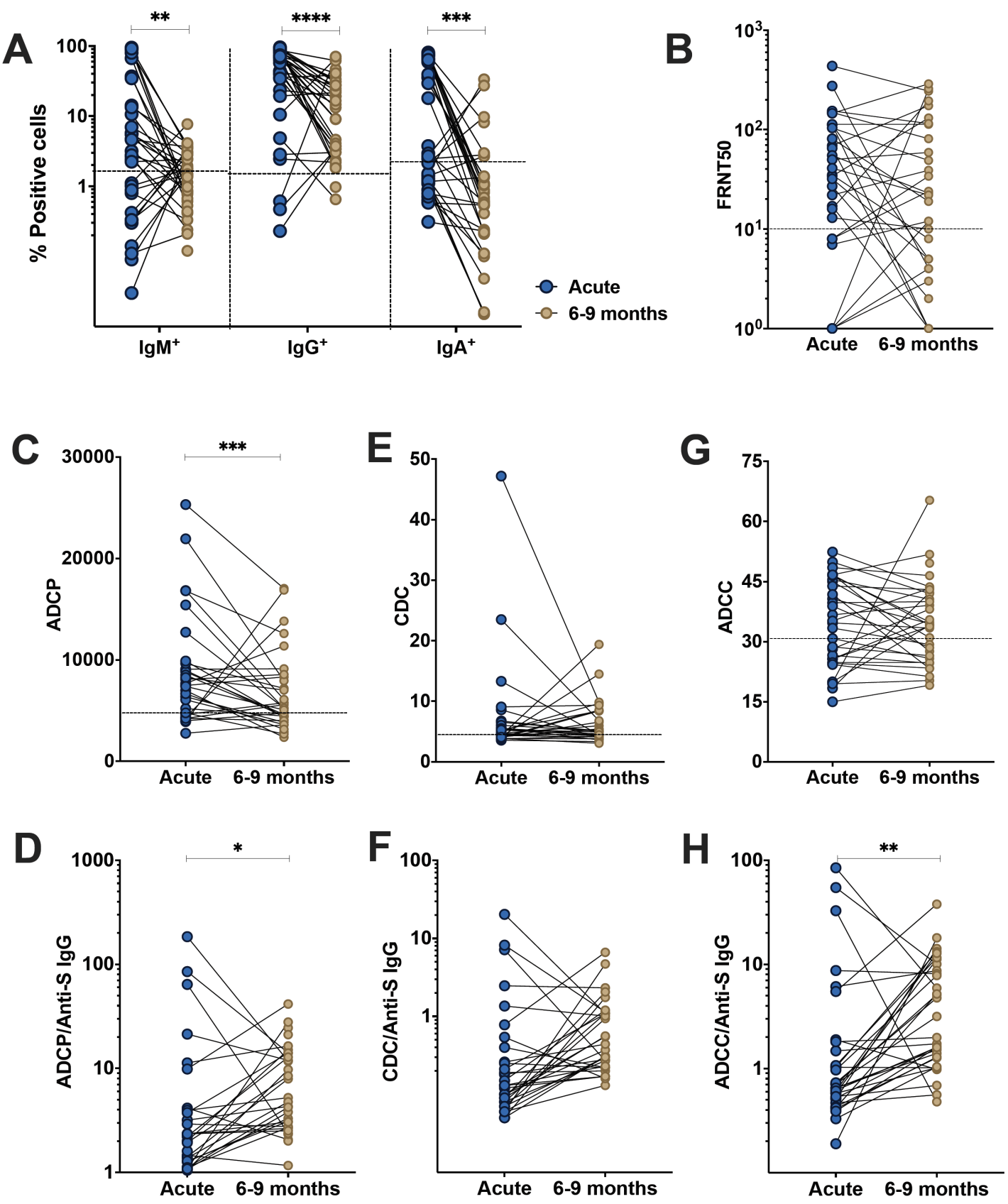


\section{Figure S3. Analysis of antibody features in paired patient samples}

16 Individuals were sampled 2-9 days post laboratory confirmation and 6-9 months later. (A)

17 Amount of antibodies against spike protein were reported as percentage of spike-expressing

18 293T cells bound by IgM, IgG, IgA in the S-Flow assay. (B) SARS-CoV-2 neutralizing activity

19 was calculated as FRNT50 titer in foci reduction neutralization test. (C) Comparison of ADCP

20 activity in SARS-CoV-2-infected individuals in the acute phase of infection and 6-9 months

21 post-infection. (D) Ratio of ADCP to anti-spike IgG measured by S-Flow. (E) Comparison of

22 CDC activity in SARS-CoV-2-infected individuals in the acute phase of infection and 6-9

23 months post infection. (F) Ratio of CDC to anti-spike IgG measured by S-Flow. (G)

24 Comparison of ADCC activity in SARS-CoV-2-infected individuals in the acute phase of

25 infection and 6-9 months post infection. (H) Ratio of ADCC to anti-spike IgG measured by S-

26 Flow. Statistical comparisons were performed by Wilcoxon test. The dashed line indicates the

27 cutoff for positivity based on values calculated following formula: cut-off $=\%$ mean positive

28 cells from 19 pre-pandemic samples $+3 x$ standard deviation. Each dot represents result from a

29 single individual. Lines represent median and IQR. Each dot represents one individual. Lines

30 represent median and IQR. $* \mathrm{p}<0.05, * * \mathrm{p}<0.01, * * * \mathrm{p}<0.001$, and $* * * * \mathrm{p}<0.0001$

31 IgM/IgA/IgG antibody: n=33, Neutralization: $n=33$, ADCP: $n=30$, CDC: $n=30$, ADCC $n=32$. 

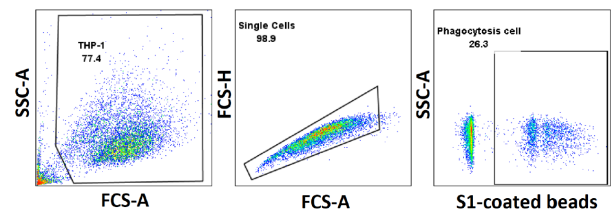

B
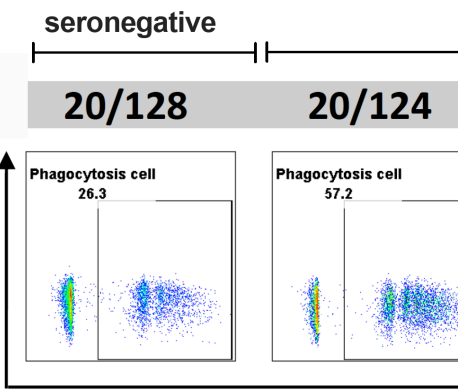

\section{$20 / 126$}

seropositive
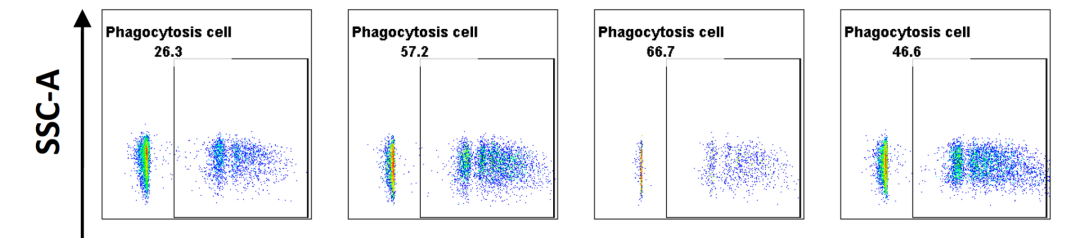

$20 / 130$

$20 / 120$

S1-coated beads

\section{Figure S4. Antibody-dependent cellular phagocytosis (ADCP) assay}

35 Quantification of the S1-coated beads engulfed by THP-1 cells. (A) Representative gating

36 strategy. (B) ADCP was defined by the percentages of THP-1 cells which are positive for FITC-

37 neutravidin beads coated with biotinylated S1 protein. Representative ADCP assay using the

38 COVID-19 reference plasma panel (NIBSC 20/120, 20/124, 20/124, 20/126, 20/128, 20/130)

39 obtained from the NIBSC. The ADCP activity represents the integrate mean fluorescence

40 intensity (iMFI) value (\% positive fluorescence THP-1 cells x MFI of the positive fluorescence

41 THP-1 cells). The experiment was performed in duplicate. 
A
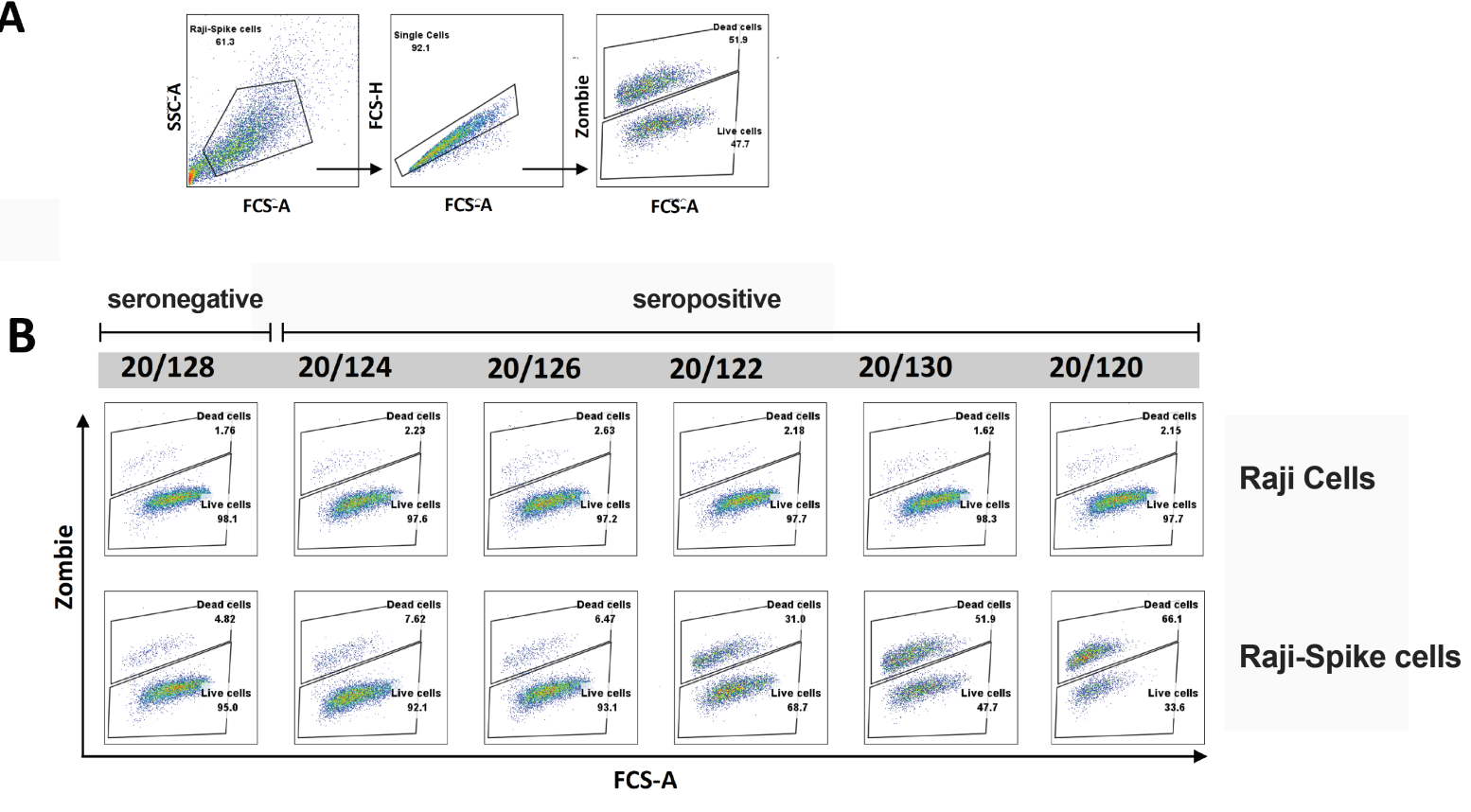

43 Figure S5. Complement-dependent cytotoxicity (CDC) assay

44 SARS-CoV-2 plasma induces C3 deposition and cell death in spike-expressing Raji cells. (A)

45 Representative gating strategy. (B) CDC assay was performed by using pike-expressing Raji

46 cells as target cells, serum (pooled from 3 healthy donors) as complement source and heat-

47 inactivated plasma from SARS-CoV-2 patients or from reference panel as antibody source.

$48 \mathrm{CDC}$ activity was measured as the percentage of $\mathrm{C}^{+} \mathrm{Zombie}^{+}$pike-expressing Raji cells after

49 incubation with plasma and complement. Representative CDC assay using the COVID-19

50 reference plasma panel (NIBSC 20/120, 20/124, 20/124, 20/126, 20/128, 20/130) obtained from

51 the NIBSC. Complement-induced cell death was calculated as percentage of $\mathrm{C}^{+}$dead cells of

52 total cells using spike-expressing Raji cells as target cell. The experiment was performed in

53 duplicate. 
A

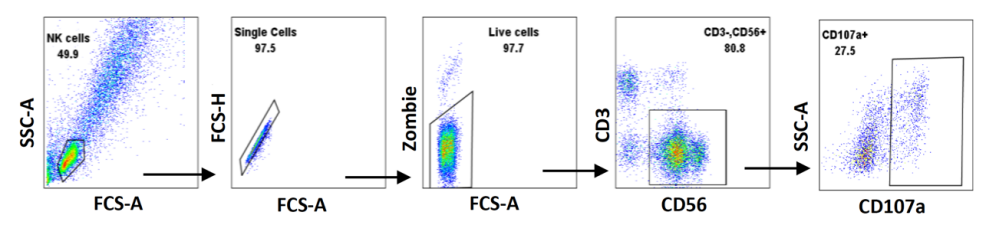

B

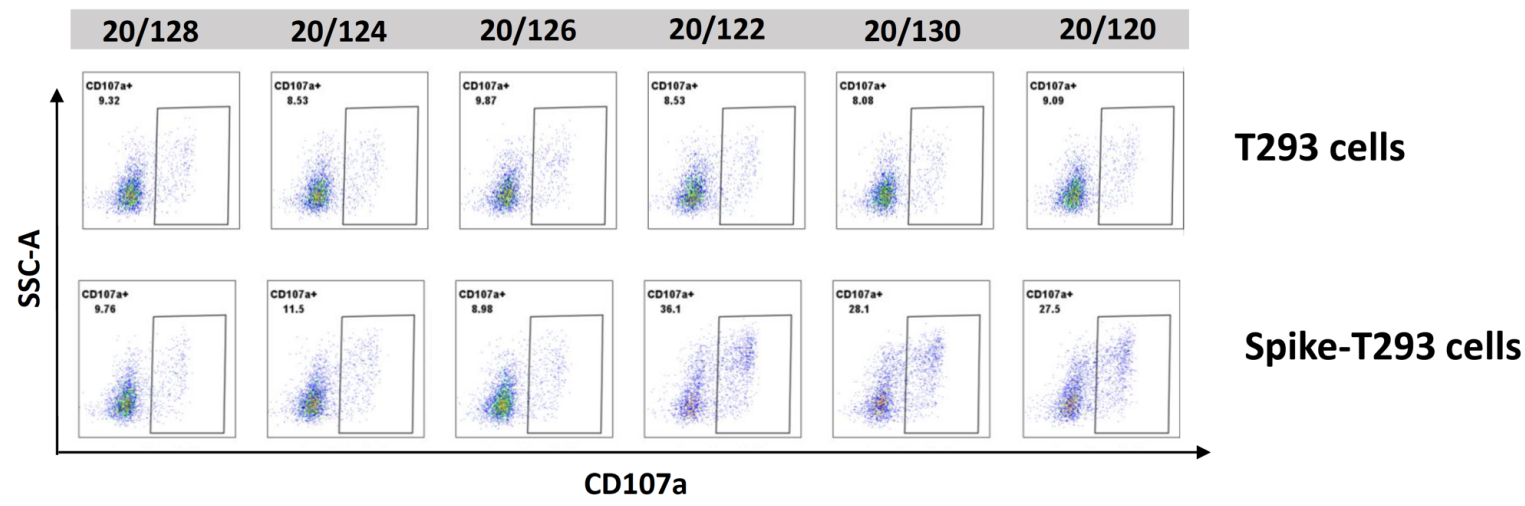

55 Figure S6. Antibody-dependent cellular cytotoxicity (ADCC) assay. (A). Representative

56 gating strategy. NK cells were identified by lymphocyte morphology, singlet, live cell and CD3-

$57 \mathrm{CD}^{2} 6^{+}$. The ADCC activity was defined based on NK cell degranulation $\left(\mathrm{CD} 107^{+}\right) .(\mathbf{B}-\mathbf{C})$

58 ADCC activity of NK cells induced by incubation with COVID-19 reference plasma panel

59 (NIBSC 20/120, 20/124, 20/124, 20/126, 20/128, 20/130) obtained from the NIBSC in the

60 presence of 293T-spike cells or 293T control cells. The experiment was performed in duplicate. 
bioRxiv preprint doi: https://doi.org/10.1101/2021.08 12 455901. this version posted August 12, 2021. The copyright holder for this preprint (which was not certified by peer review) is the author/funder, who has granted bioRxiv a license to display the preprint in perpetuity. It is made available under aCC-BY-ND 4.0 International license.

\section{A}
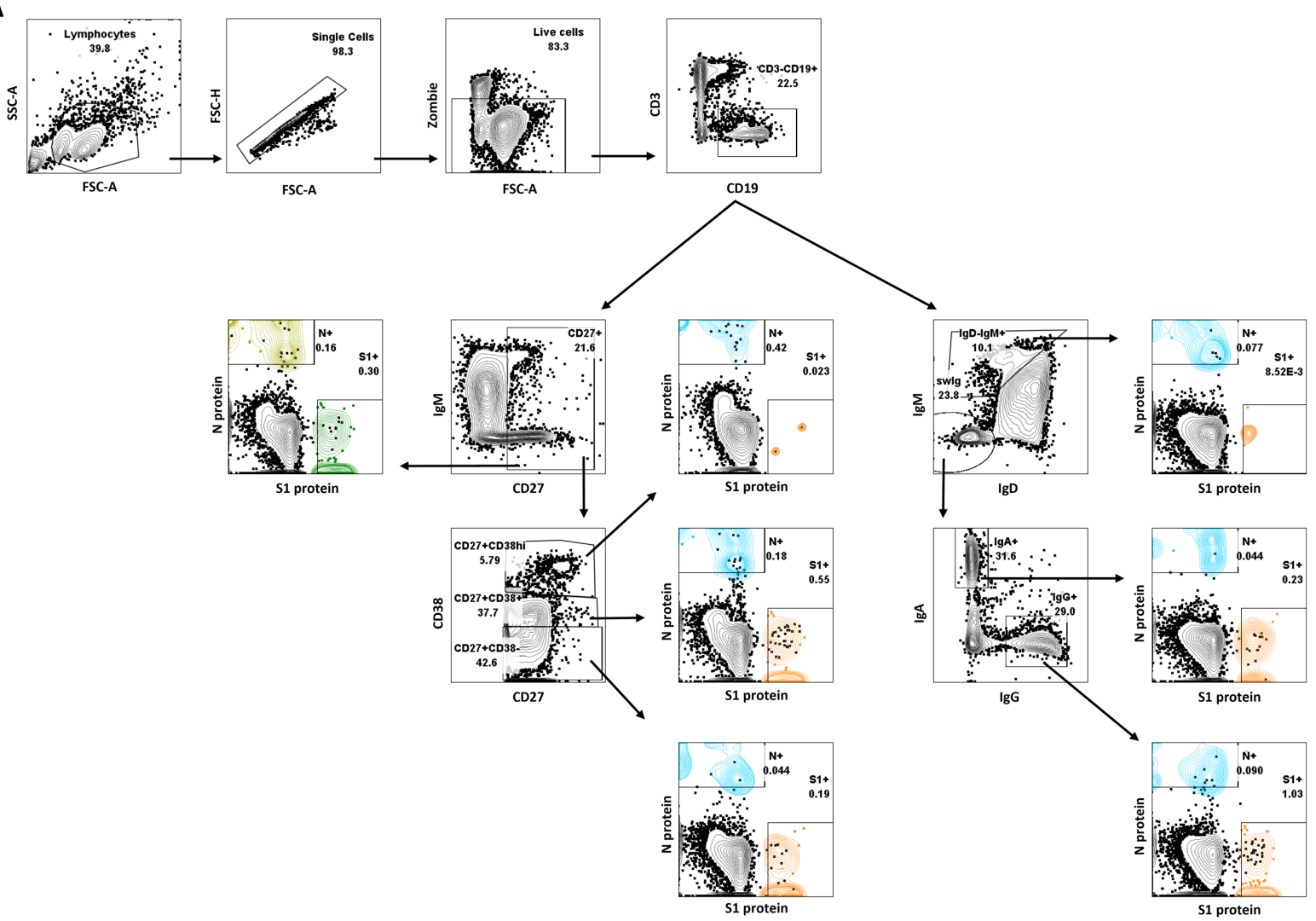

B

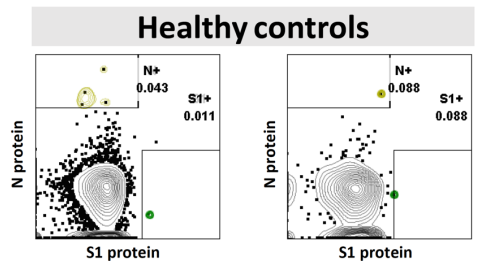

\section{Covid-19 patients}
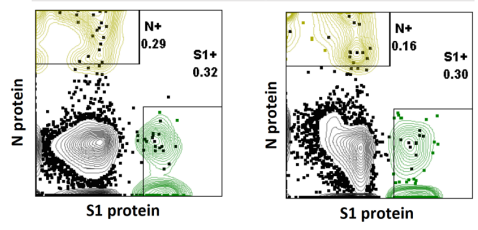
62 Figure S7. Representative gating strategy used to define antigen-specific B cells.

63 (A) B cells were defined from the gates of morphology of lymphocytes, singlets, viability and

$64 \mathrm{CD}^{-} \mathrm{CD} 19^{+}$. (B). Total B cells $\left(\mathrm{CD} 19^{+}\right)$were further gated for B cell subsets including resting

65 memory B cells $\left(\mathrm{CD} 27^{+} \mathrm{CD} 38^{-}\right)$, activated memory B cells $\left(\mathrm{CD} 27^{+} \mathrm{CD} 38^{+}\right)$and plasma blasts

66 (CD27 $7^{+}$D38 $\left.{ }^{\text {hi }}\right)$. S1-specific B cells and N-specific B cells were determined. (C) Total B cells

$67\left(\mathrm{CD} 19^{+}\right)$were further gated for B cell classes including non-class-switched mature cells $\left(\mathrm{IgD}^{-}\right.$

$68 \operatorname{IgM}^{+}$) and class-switched $\operatorname{IgM}^{-} \operatorname{IgD}^{-} \operatorname{IgA}{ }^{+}$and $\operatorname{IgM}^{-} \operatorname{IgD}^{-} \operatorname{IgG}^{+}$cells. The $\mathrm{S} 1$-specific B cells and

69 N-specific B cells were determined. (D) Representative image comparing S1- and N-specific B

70 cells in healthy controls and SARS-CoV-2-infected patients 6-9 months post infection. 
bioRxiv preprint doi: https://doi.org/10.1101/2021.08.12.455901; this version posted August 12, 2021. The copyright holder for this preprint (which was not certified by peer review) is the author/funder, who has granted bioRxiv a license to display the preprint in perpetuity. It is made available under aCC-BY-ND 4.0 International license.
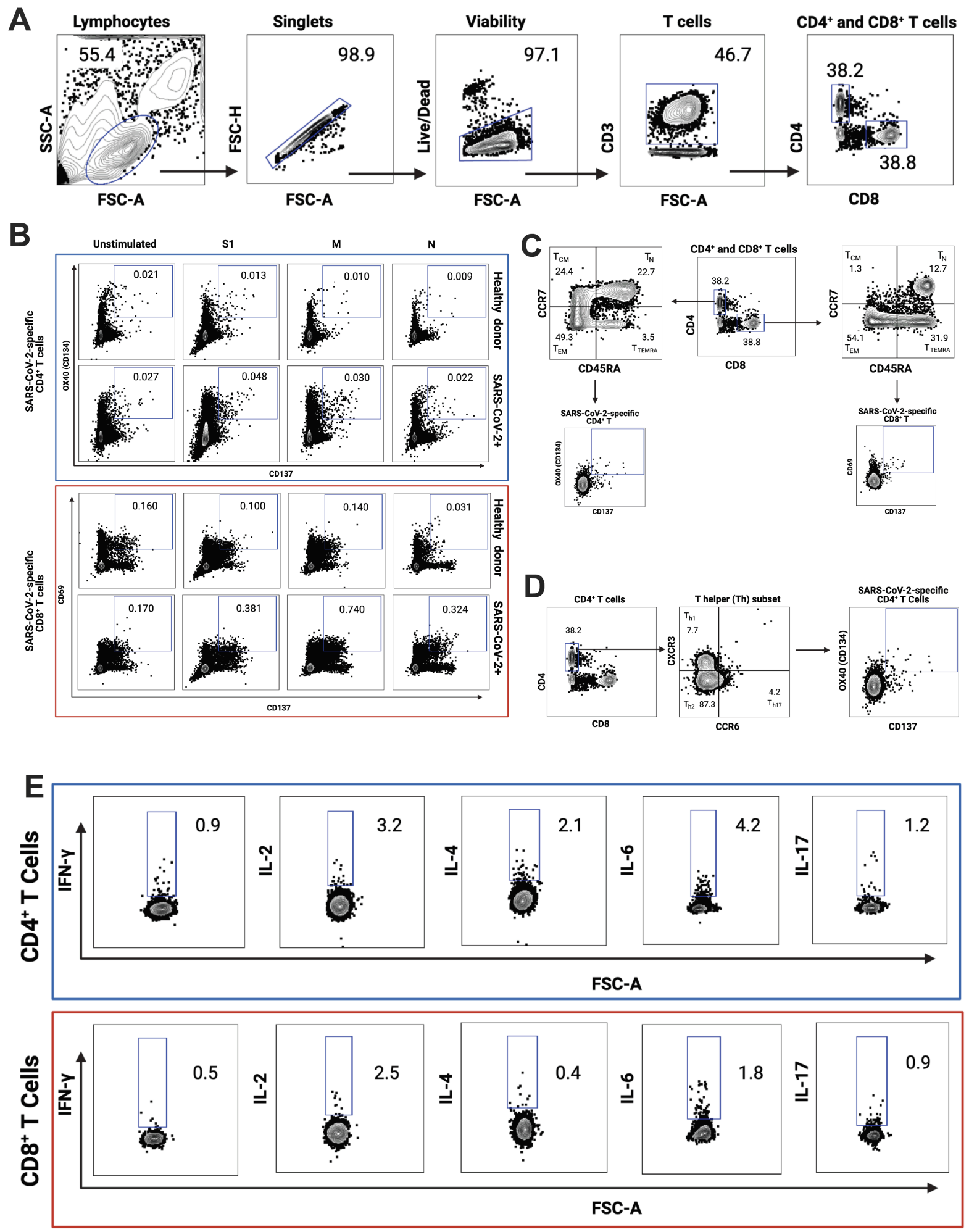
72 Figure S8. Representative gating strategy used for the $\mathbf{T}$ cells assays. (A) $\mathrm{T}$ cells were

73 defined from the gates of morphology of lymphocytes, singlets, viability and CD ${ }^{+}$. (B) Gating

74 strategy used in the $\mathrm{CD}^{+}$and $\mathrm{CD}^{+} \mathrm{T}$ cell activation induced marker (AIM) assay to assess the

75 SARS-CoV-2-specific $\mathrm{CD}^{+}$and $\mathrm{CD}^{+} \mathrm{T}$ cells after overnight stimulation with $\mathrm{S}, \mathrm{M}$ and $\mathrm{N}$

76 peptide pools. Representative image comparing S-, $\mathrm{M}-$ and $\mathrm{N}$-specific $\mathrm{CD}^{+}$and $\mathrm{CD}^{+} \mathrm{T}$ cells

77 in a healthy control and a SARS-CoV-2-infected patient 6-9 months post infection. (C) Gating

78 strategy used in the $\mathrm{CD}^{+}$and $\mathrm{CD}^{+} \mathrm{T}$ cell activation induced marker (AIM) assay to assess the

79 SARS-CoV-2-specific memory $\mathrm{CD}^{+}$and $\mathrm{CD}^{+} \mathrm{T}$ cell subsets. Distribution of central memory

80 (TCM), effector memory (TEM), and terminally differentiated effector memory cells

81 (TEMRA) among total SARS-CoV-2-specific T cells. (D) Gating strategy used in the CD4 ${ }^{+} \mathrm{T}$

82 cell activation induced marker (AIM) assay to assess SARS-CoV-2-specific T helper (Th)

83 subsets. (E) Gating strategy used in the $\mathrm{CD} 4^{+}$and $\mathrm{CD}^{+} \mathrm{T}$ cell intracellular staining assay to

84 assess the cellular cytokine profile after 6 hours stimulation with $\mathrm{S}, \mathrm{M}$ and $\mathrm{N}$ peptide pools. 
bioRxiv preprint doi: https://doi.org/10.1101/2021.08.12,455901; this version posted August 12, 2021. The copyright holder for this preprint (which was not certified by peer review) is the author/funder, who has granted bioRxiv a license to display the preprint in perpetuity. It is made available under aCC-BY-ND 4.0 International license.

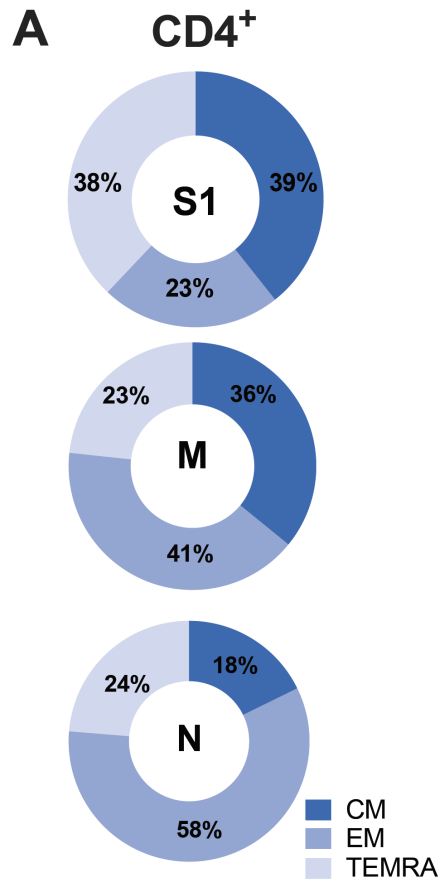

D CD8 $^{+}$

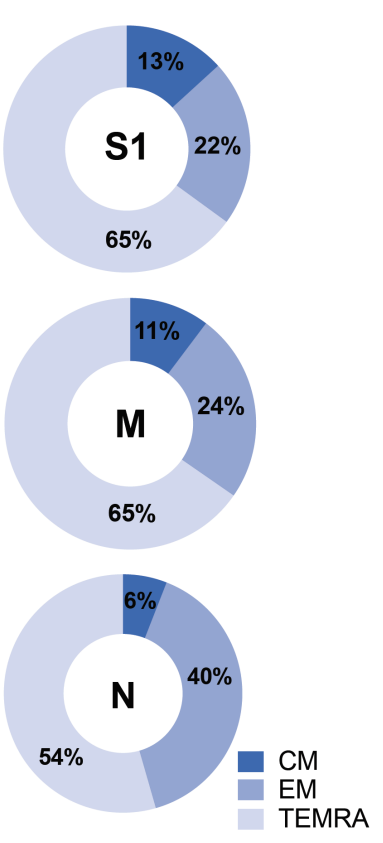

$\mathbf{B}$
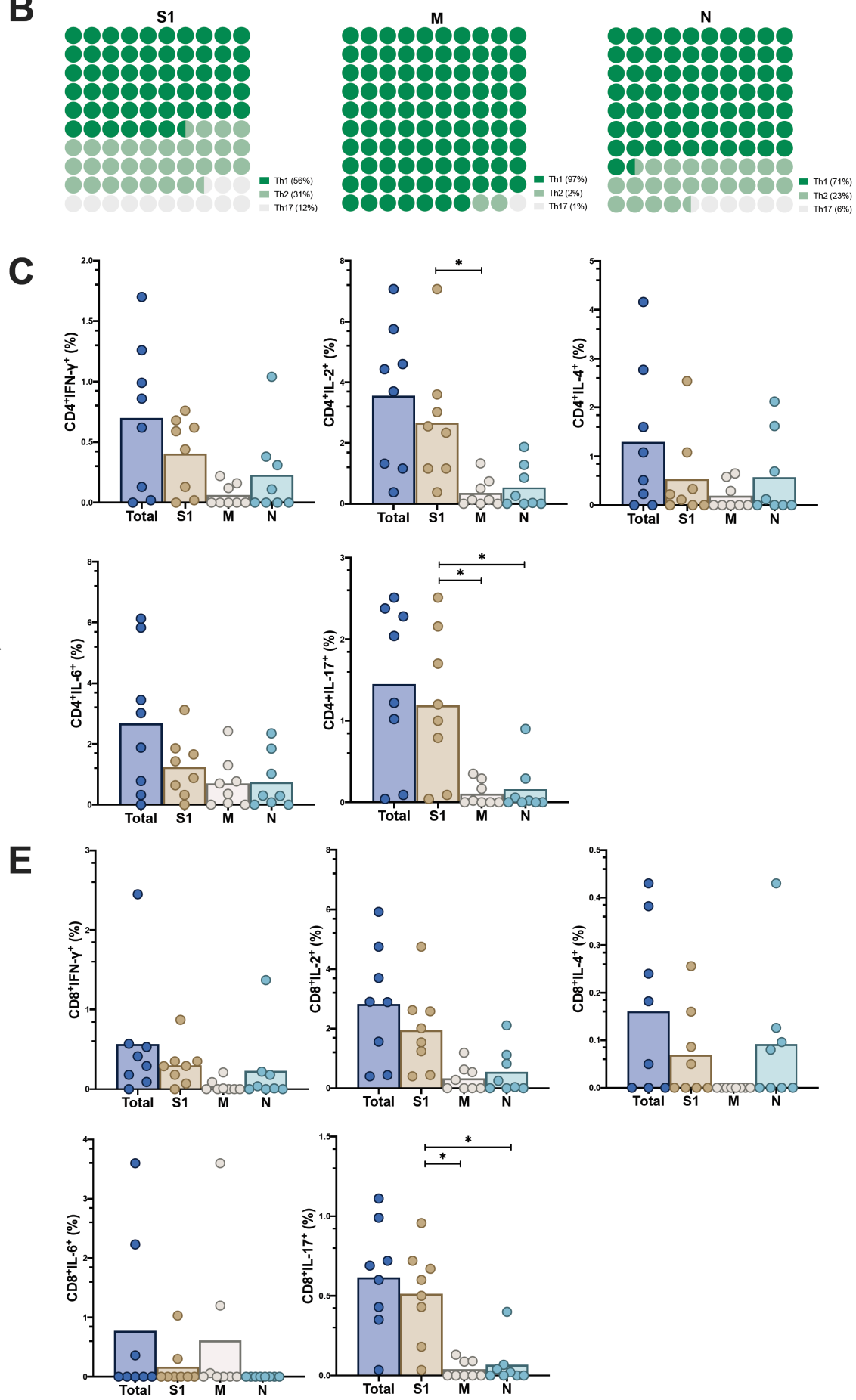
86 Figure S9. Characterization of SARS-CoV-2-specific T Cells. (A) Distribution of central

87 memory (TCM), effector memory (TEM), and terminally differentiated effector memory cells

88 (TEMRA) $\mathrm{CD}^{+} \mathrm{T}$ cells targeting different proteins of SARS-CoV-2 after overnight stimulation

89 with different peptide pools. (B) The $\mathrm{CD}^{+}$Th differentiation, targeting different proteins of

90 SARS-CoV-2, after overnight stimulation with different peptide pools. (C) Cytokine profile of

$91 \mathrm{CD}^{+} \mathrm{T}$ cells after 6 hours stimulation with S, M and N peptide pools. (D) Distribution of central

92 memory (TCM), effector memory (TEM), and terminally differentiated effector memory cells

93 (TEMRA) $\mathrm{CD}^{+} \mathrm{T}$ cells targeting different proteins of SARS-CoV-2, after overnight

94 stimulation with different peptide pools. (E) Cytokine profile of $\mathrm{CD}^{+} \mathrm{T}$ cells after 6 hours

95 stimulation with $\mathrm{S}, \mathrm{M}$ and $\mathrm{N}$ peptide pools. 

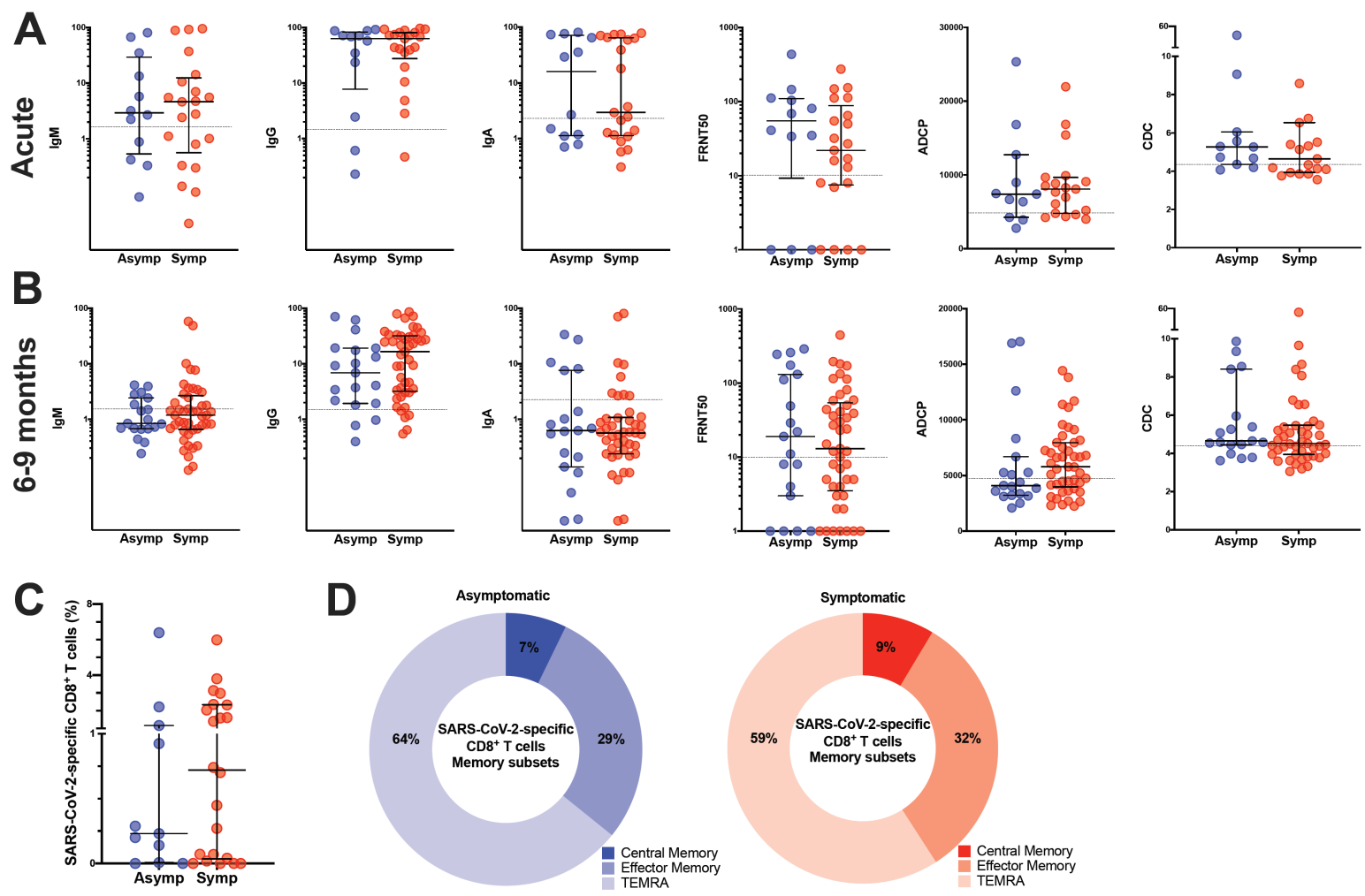

97 Figure S10. Comparison of immune parameters in asymptomatic and symptomatic

98 individuals. Comparison of anti-S antibody titers, FRNT50 titers and anti-S mediated effector

99 functions in the (A) acute phase and (B) late convalescent phase after infection. (C) Comparison

100 of the frequency of total SARS-CoV-2-specific $\mathrm{CD}^{+} \mathrm{T}$ cells after overnight stimulation with

101 peptide pools in asymptomatic individuals (asymp; $\mathrm{n}=11$ ) and symptomatic patients (symp; $102 \mathrm{n}=22$ ) at late convalescence. (D) Comparison of $\mathrm{CD}^{+} \mathrm{T}$ cell memory phenotype between 103 asymptomatic individuals (asymp; $\mathrm{n}=11$ ) and symptomatic patients (symp; $\mathrm{n}=22$ ). 
104 Table S1: Cohort description.

\section{SARS-CoV-2-infected} patients $(n=64)$

\begin{tabular}{lc}
\hline \hline Age (y), median (min-max, IQR) & $36(12-75,18.5)$ \\
\hline Sex (\%) & $55(86)$ \\
Male & $9(14)$ \\
Female & $8(13)$ \\
\hline Smoker (\%) & \\
\hline Comorbidities (\%) & $2(3)$ \\
Diabetes & $7(11)$ \\
High blood pressure & \\
\hline Clinical spectrum (\%) & $19(30)$ \\
Asymptomatic & $45(70)$ \\
Symptomatic & $15(23)$ \\
$\quad$ Dysosmia and dysgeusia & $16(25)$ \\
Dyspnea & $23(36)$ \\
Fever & $35(55)$ \\
Cough or sore throat or running nose & $5(2-9)$ \\
Acute & $203(166-258)$ \\
6-9 months & $30(47)$ \\
\hline Time of SARS-CoV-2 RNA shedding (\%) & $34(53)$ \\
< 10 days positive & \\
$\geq 10$ days positive & \\
\hline \hline
\end{tabular}


106 Table S2: Monoclonal antibody list.

\begin{tabular}{|c|c|c|c|}
\hline Marker & Fluorochrome & Supplier & Catalog N. \\
\hline C3/C3b/iC3b & APC & Cedarlane & CL7503APC \\
\hline CCR6 & BB515 & BD Biosciences & 564479 \\
\hline CCR7 & APC & Biolegend & 353214 \\
\hline CD107a & APC & BD Biosciences & 560664 \\
\hline CD134 & BB700 & BD Biosciences & 566559 \\
\hline CD137 & PE-Cy7 & Biolegend & 309818 \\
\hline CD138 & BV785 & Biolegend & 356538 \\
\hline CD19 & APC/Cy7 & Biolegend & 302218 \\
\hline CD27 & PerCP/Cy5.5 & Biolegend & 356408 \\
\hline CD3 & BUV395 & BD Biosciences & 564001 \\
\hline CD3 & Per-Cp5-5 & Biolegend & 317336 \\
\hline CD38 & BV 605 & Biolegend & 303532 \\
\hline CD4 & BUV496 & BD Biosciences & 612936 \\
\hline CD45RA & BV421 & Biolegend & 304130 \\
\hline CD56 & BV421 & Biolegend & 362552 \\
\hline CD69 & BV786 & Biolegend & 310932 \\
\hline CD69 & PE-Cy7 & Biolegend & 310912 \\
\hline CD8 & AF700 & Biolegend & 344724 \\
\hline CD8 & APC-H7 & BD Biosciences & 560179 \\
\hline CXCR3 & BV711 & Biolegend & 353732 \\
\hline IFN-y & BV605 & Biolegend & 502536 \\
\hline IFN-y & PE & Biolegend & 506507 \\
\hline $\lg A$ & APC & Miltenyi Biotec & $130-113-472$ \\
\hline $\lg A$ & AF 647 & Jackson ImmunoResearch & $109-605-011$ \\
\hline $\lg D$ & BV711 & BD Biosciences & 740794 \\
\hline $\lg G$ & APC & Life technology & A21445 \\
\hline $\lg G$ & FITC & Biolegend & 410720 \\
\hline $\lg M$ & PE & Biolegend & 314508 \\
\hline $\lg M$ & BV421 & Biolegend & 314515 \\
\hline IL-17 & BV711 & Biolegend & 512328 \\
\hline IL-2 & PerCP/Cy.5 & Biolegend & 500322 \\
\hline IL-4 & BUV737 & BD Biosciences & 612835 \\
\hline IL-6 & PE & Biolegend & 501107 \\
\hline TNF- $\alpha$ & APC-Cy7 & Biolegend & 502944 \\
\hline
\end{tabular}




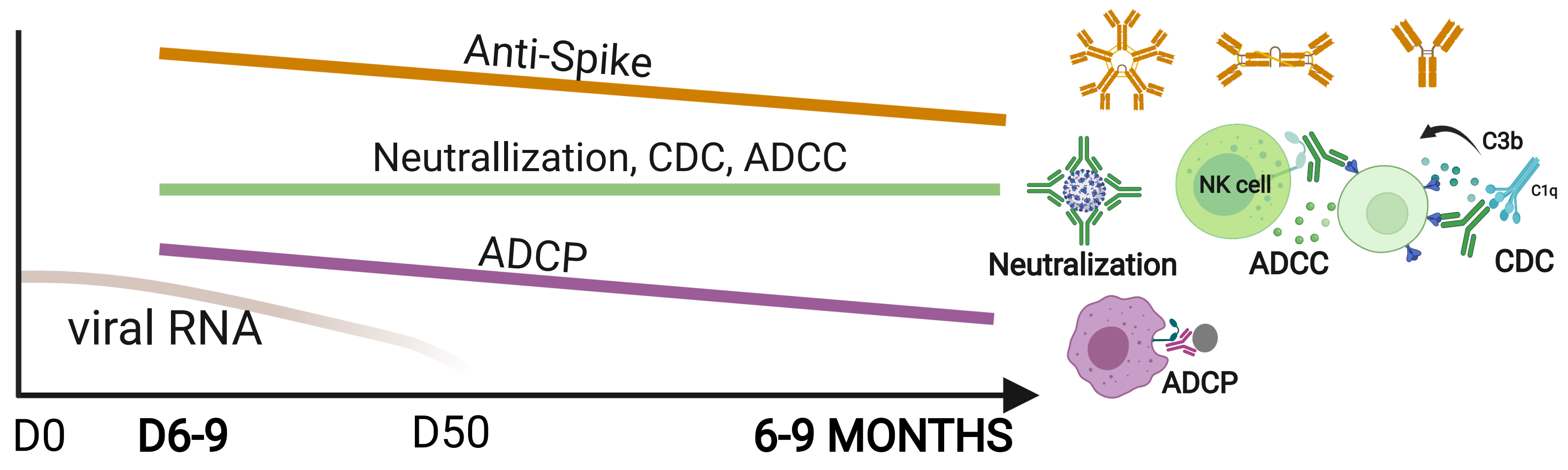

bioRxiv preprint doi: https://doi.org/10.1101/2021.08.12.455901; this version posted Aur
(which was not certified by peer review) is the author/funder, who has granted bioRxiv a ll
available under aCC-BY-ND 4.0 International heense.
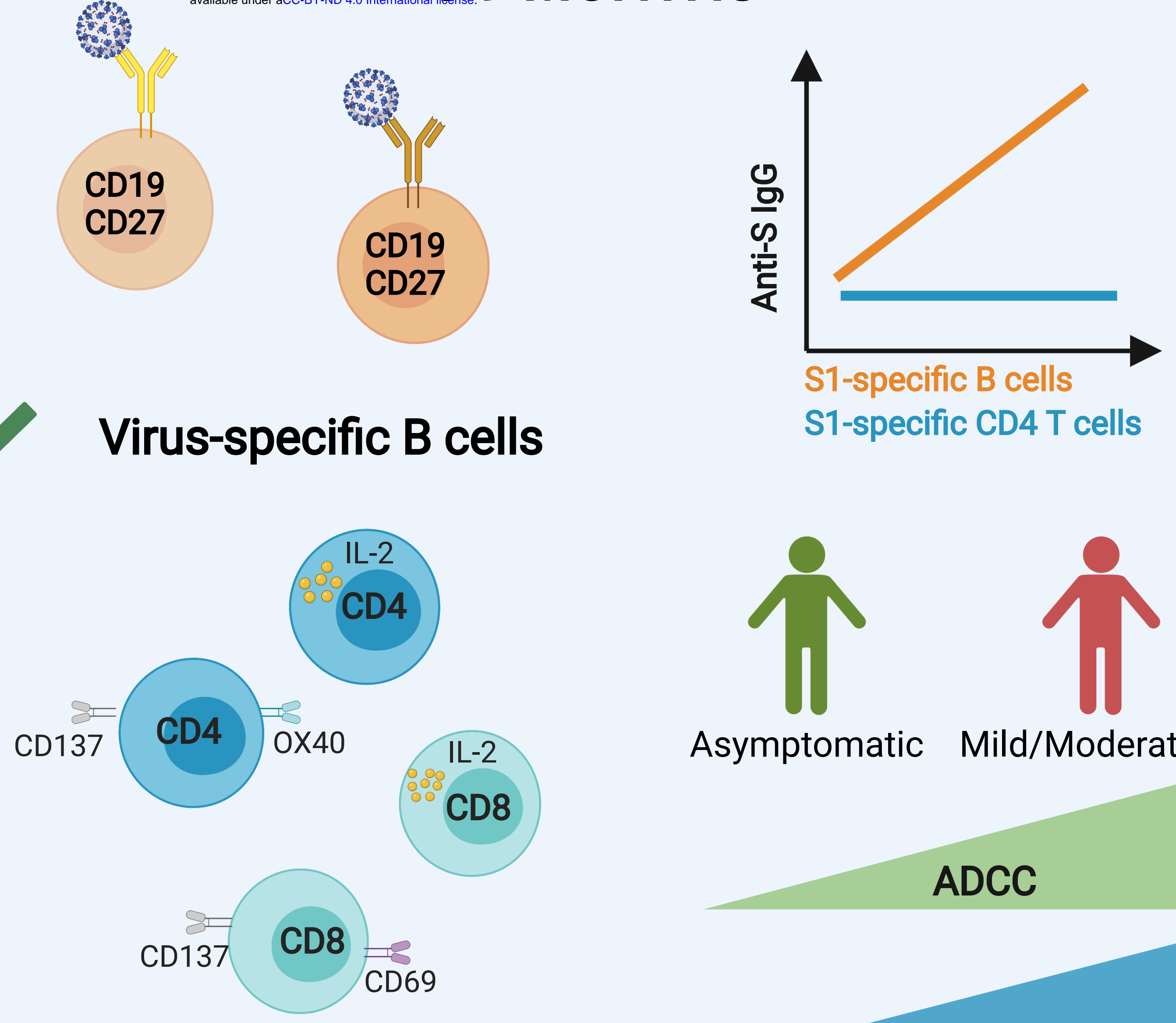

Asymptomatic Mild/Moderate

Virus-specifc T cells

\section{ADCC}

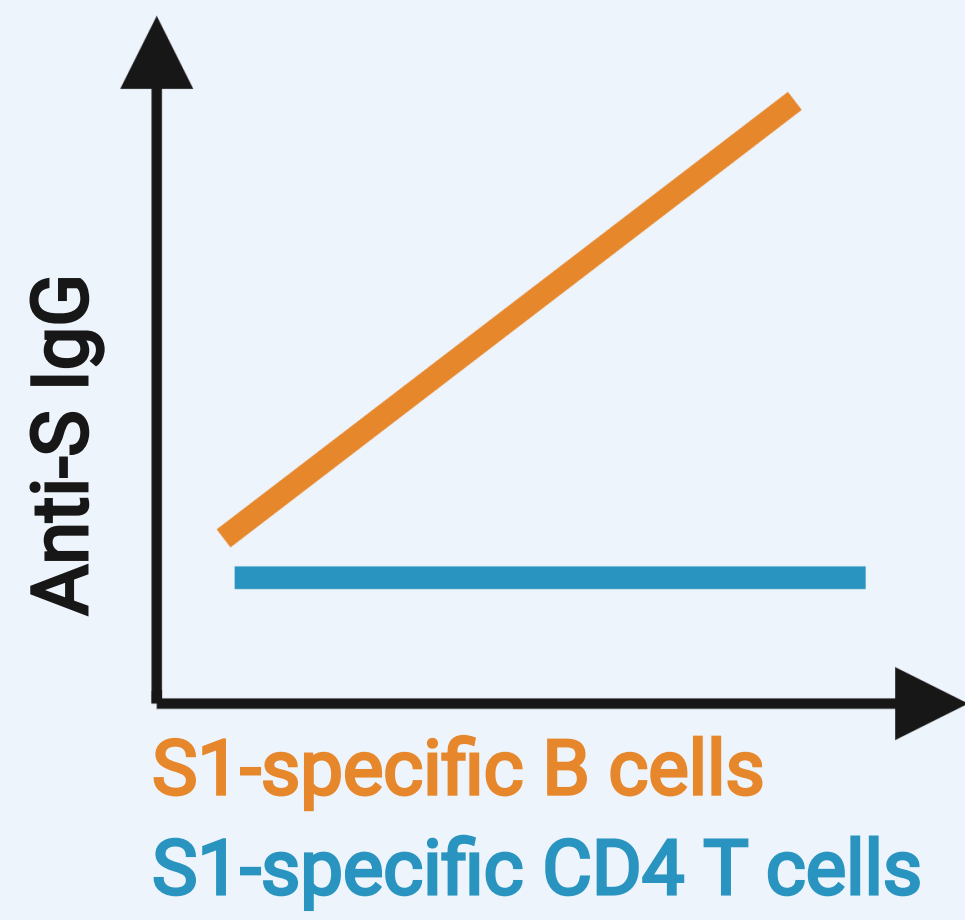

